\title{
A striking new genus and species of cave-dwelling frog (Amphibia: Anura: Microhylidae: Asterophryinae) from Thailand
}

Chatmongkon Suwannapoom ${ }^{1}$, Montri Sumontha ${ }^{\text {Corresp., }}{ }^{2}$, Jitthep Tunprasert ${ }^{3}$, Thiti Ruangsuwan ${ }^{4}$, Parinya Pawangkhanant ${ }^{1}$, Dmitriy V Korost ${ }^{5}$, Nikolay A Poyarkov ${ }^{\text {Corresp. } 6,7}$

${ }^{1}$ Division of Fishery, School of Agriculture and Natural Resources, University of Phayao, Phayao, Thailand

2 Department of Fishery, Ranong Marine Fisheries Station, Ranong, Thailand

3 Department of ecology, Nakhon Pathom Rajabhat University, Nakhon Pathom Mueng, Nakhon Pathom, Thailand

4 Department of Zoology, Faculty of Science, Kasetsart University, Bangkok, Thailand

5 Petroleum Geology Department, Geological Faculty, Moscow State University, Moscow, Russia

6 Biological Faculty, Department of Vertebrate Zoology, Moscow State University, Moscow, Russia

7 Laboratory of Tropical Ecology, Joint Russian-Vietnamese Tropical Research and Technological Center, Hanoi, Vietnam

Corresponding Authors: Montri Sumontha, Nikolay A Poyarkov

Email address: montri.sumontha@gmail.com,n.poyarkov@gmail.com

We report on a discovery of Siamophryne troglodytes Gen. et sp. nov. - a new troglophilous genus and species of microhylid frog from a limestone cave in the tropical forests of western Thailand. To assess its phylogenetic relationships we studied $12 \mathrm{~S}$ rRNA-16S rRNA mtDNA fragment with final alignment comprising up to $2591 \mathrm{bp}$ for 56 microhylid species. Morphological characterization of the new genus is based on examination of external morphology and analysis of osteological characteristics using microCT-scanning. Phylogenetic analyses place the new genus into the mainly Australasian subfamily Asterophryinae as a sister taxon to the genus Gastrophrynoides, the only member of the subfamily known from Sundaland. The new genus markedly differs from all other Asterophryinae members by a number of diagnostic morphological characters and demonstrates significant mtDNA sequence divergence. We provide a preliminary description of a tadpole of the new genus. Thus, it represents the only asterophryine taxon with documented free-living larval stage and troglophilous life style. Our work demonstrates that Siamophryne troglodytes Gen. et sp. nov. represents an old lineage of the initial radiation of Asterophryinae which took place in the mainland Southeast Asia. Our results strongly support the "out of Indo-Eurasia" biogeographic scenario for this group of frogs. To date, the new frog is only known from a single limestone cave system in Sai Yok District of Kanchanaburi Province of Thailand; its habitat is affected by illegal bat guano mining and other human activities. As such, Siamophryne troglodytes Gen. et sp. nov. is likely to be at high risk of habitat loss. Considering high ecological specialization and a small known range of the new taxon, we propose a IUCN Red List status of Endangered 
(EN) for it. 
$1 \quad$ A striking new genus and species of cave-dwelling frog

2

3

4

5

6

7

8

9

10

11

(Amphibia: Anura: Microhylidae: Asterophryinae) from Thailand

Chatmongkon Suwannapoom ${ }^{1}$, Montri Sumontha ${ }^{2 *}$, Jitthep

Tunprasert ${ }^{3}$, Thiti Ruangsuwan ${ }^{4}$, Parinya Pawangkhanant ${ }^{1}$, Dmitriy V. Korost $^{5}$, Nikolay A. Poyarkov, Jr. ${ }^{6,7^{*}}$

1 Division of Fishery, School of Agriculture and Natural Resources, University of Phayao, Phayao, Thailand

2 Department of Fishery, Ranong Marine Fisheries Station, Ranong, Thailand

3 Department of ecology, Nakhon Pathom Rajabhat University, Nakhon Pathom Mueng, Nakhon Pathom, Thailand

4 Department of Zoology, Faculty of Science, Kasetsart University, Bangkok, Thailand

5 Petroleum Geology Department, Geological Faculty, Moscow State University, Moscow, Russia

6 Biological Faculty, Department of Vertebrate Zoology, Moscow State University, Moscow, Russia

7 Laboratory of Tropical Ecology, Joint Russian-Vietnamese Tropical Research and Technological Center, Hanoi, Vietnam

* Corresponding authors: Nikolay A Poyarkov, Montri Sumontha

Email address: n.poyarkov@gmail.com, montri.sumontha@gmail.com

\section{Abstract}

We report on a discovery of Siamophryne troglodytes Gen. et sp. nov. - a new troglophilous genus and species of microhylid frog from a limestone cave in the tropical forests of western Thailand. To assess its phylogenetic relationships we studied 12S rRNA-16S rRNA mtDNA fragment with final alignment comprising up to $2591 \mathrm{bp}$ for 56 microhylid species. Morphological characterization of the new genus is based on 
29 examination of external morphology and analysis of osteological characteristics using

30

31 microCT-scanning. Phylogenetic analyses place the new genus into the mainly Australasian subfamily Asterophryinae as a sister taxon to the genus Gastrophrynoides, the only member of the subfamily known from Sundaland. The new genus markedly differs from all other Asterophryinae members by a number of diagnostic morphological characters and demonstrates significant mtDNA sequence divergence. We provide a preliminary description of a tadpole of the new genus. Thus, it represents the only asterophryine taxon with documented free-living larval stage and troglophilous life style. Our work demonstrates that Siamophryne troglodytes Gen. et sp. nov. represents an old lineage of the initial radiation of Asterophryinae which took place in the mainland Southeast Asia. Our results strongly support the "out of Indo-Eurasia" biogeographic scenario for this group of frogs. To date, the new frog is only known from a single limestone cave system in Sai Yok District of Kanchanaburi Province of Thailand; its habitat is affected by illegal bat guano mining and other human activities. As such, Siamophryne troglodytes Gen. et sp. nov. is likely to be at high risk of habitat loss. Considering high ecological specialization and a small known range of the new taxon, we propose a IUCN Red List status of Endangered (EN) for it.

\section{Introduction}

Microhylidae is one of the largest frog families belonging to the Ranoidea, with a pan-tropical distribution. To date, it includes 641 species (nearly $9.4 \%$ of anuran diversity) (Frost, 2017). Microhylid frogs occur on most of the continents and several large islands, their range encompasses tropical and subtropical areas of Southern and Northern America, Africa, Madagascar, South, Southeast and East Asia, Australasian islands and northern Australia. Family-level taxonomy of Microhylidae is considered to be a "phylogeneticist's nightmare" (Peloso et al., 2017) and is the subject of numerous studies and an on-going debate. At present, 13 subfamilies are recognized based on morphological and molecular phylogenetic data (Matsui et al., 2011; Pyron \& Wiens, 
57 2011; Kurabayashi et al., 2011; de Sá et al., 2012; Peloso et al., 2017). However, the

58 degree of coherence between the morphological and molecular classifications of the

59 family is quite low due to the high morphological variation and widespread convergence

60 in microhylids, which, in many cases, likely is connected to specializations associated

61 with a burrowing lifestyle (see de Sá et al., 2012; Peloso et al., 2017). The basal split

62 within Microhylidae is estimated to coincide with the Cretaceous-Paleogene boundary

63 (65 Ma) (Feng et al., 2017); previous studies argued for Mesozoic origin of Microhylidae

64 and considered the constituent subfamilies as full families of Anura (Bossuyt \& Roelants, 65 2009).

66

Each Microhylidae subfamily is restricted to a landmass derived from the breaking up of the Gondwana: the Americas (subfamilies Adelastinae, Gastrophryninae and Otophryninae), Africa (subfamilies Hoplophryninae and Phrynomerinae), Madagascar (subfamilies Cophylinae, Dyscophinae and Scaphiophryninae), India (subfamily Melanobatrachinae), East, South and Southeast Asia (subfamilies Chaperininae, Kalophryninae and Microhylinae) and Australasia (subfamily Asterophryinae) (Kurabayashi et al., 2011; de Sá et al., 2012; Peloso et al., 2017). Due to their transcontinental pantropical distribution, Microhylidae were regarded as a promising model group for biogeography studies (Savage, 1973). Most previous works, though varying on taxon sampling and molecular data, suggested that Microhylidae are of Gondwanan origin and gave evidence supporting the "Antarctic route scenario" for the Australasian subfamily Asterophryinae, as suggested for several other vertebrate taxa that are distributed in Australia (Van Bocxlaer et al., 2006; Van der Meijden et al., 2007). According to this scenario, the basal split of Microhylidae took place in Gondwana and the ancestor of Asterophryinae dispersed to Australia via Antarctic land bridge (Hill, 2009), where the subfamily diversified (it comprises 323 recognized species to date, Frost, 2017) and subsequently dispersed to New Guinea and adjacent Australasian islands, but was unable to cross the Wallace line with exception of the genus Oreophryne Boettger, which is also known from the island of Bali (west from the Wallace line, see Fig. 1). 
86

87

88

89

90

91

92

93

94

95

96

97

However, for the first time, Matsui et al. (2011) reported on the phylogenetic position of the enigmatic genus Gastrophrynoides Noble inhabiting Sundaland (peninsular Malaysia and northern Borneo, see Fig. 1), which was not yet assigned to any certain subfamily. Based on the analysis of $16 \mathrm{~S}$ rRNA - 12S rRNA mtDNA data it was established as a sister lineage of the genus Oreophryne (Asterophryinae). Association of Gastrophrynoides with asterophryines was further suggested by Kurabayashi et al. (2011), what allowed the authors to assign Gastrophrynoides to the subfamily Asterophryinae and propose an alternative biogeographic scenario for the group. According to Kurabayashi et al. (2011), Gastrophrynoides separated from other asterophryines around $48 \mathrm{Ma}$, while the presence of the most basal asterophryine taxon in the Eurasian area (Sundaland) suggests that the colonization route of Asterophryinae goes from Asia to Australia, but not via Antarctica as was suggested earlier. Further studies, applying multilocus (de Sá et al., 2012) and phylogenomic (Peloso et al., 2017) approaches, strongly supported the placement of the Sundanese Gastrophrynoides as a sister group to all other genera of the subfamily inhabiting Australasia.

As Kurabayashi et al. (2011:9) stated: "the biogeographic findings on Gastrophrynoides imply the possible occurrence of further microhylid taxa with unexpected evolutionary backgrounds and give a basis for future paleontological and biogeographic studies of Asian anurans". In 2016, during a field survey in a limestone cave system in Kanchanaburi Province of western Thailand, we encountered an unusually-looking troglophilous frog. It was assigned to the family Microhylidae due to the presence of the following traits: lack of maxillary teeth, lack of parotoid glands, and a firmisternal pectoral girdle with non-overlapping epicoracoids, well developed coracoids reaching the midline of the girdle and scapulae, a large, cartilaginous sternum, reduced clavicles and no omosternum. However, the new frog was morphologically distinct from any genus of Microhylidae known to occur in Thailand or adjacent parts of Indochina. Further detailed morphological, osteological and phylogenetic analyses indicated that the Microhylidae Gen. sp. from Kanchanaburi represents a new yet undescribed genus of Asterophryinae frogs, a sister taxon to Gastrophrynoides. We provide the description of 
115 this new frog herein. As we demonstrate below, our discovery carries important

116 biogeographic implications: highlights the initial radiation of Asterophryinae, which took 117 place in the mainland Southeast Asia, and supports the "out of Indo-Eurasia" 118 biogeographic scenario for this group of frogs.

119

120

121

122

123

124

125

126

127

128

129

130

131

132

133

134

135

136

137

138

139

140

141

142

\section{Materials and methods}

\section{Sample collection}

Field work was conducted from August to October of 2016 in Sai Yok District, Kanchanaburi Province, northern Tenasserim Region, western Thailand (approximate geographic coordinates: $14.476^{\circ} \mathrm{N}, 98.853^{\circ} \mathrm{E}$; elevation $-440 \mathrm{~m}$ a.s.1.). Geographic coordinates and elevation were obtained using a Garmin GPSMAP 60CSx and recorded in the WGS 84 datum. In total, 11 adult specimens (6 males and 5 gravid females) and a single tadpole of a new microhylid frog were collected and photographed in life before being euthanized using $20 \%$ solution of benzocaine prior to fixation in $96 \%$ ethanol and were subsequently stored in $70 \%$ ethanol. The larval specimen was fixed and subsequently stored in $4 \%$ formalin. Tissue samples for genetic analysis were taken prior to preservation and were stored in $95 \%$ ethanol. Specimens and tissues were subsequently deposited in the herpetological collections of the School of Agriculture and Natural Resources, University of Phayao (AUP, Phayao, Thailand) and of the Zoological Museum of Moscow University (ZMMU, Moscow, Russia).

Specimens collection protocols and animal use were approved by the Institutional Ethical Committee of Animal Experimentation of the University of Phayao, Phayao, Thailand (certificate number UP-AE59-01-04-0022 issued to Chatmongkon Suwannapoom) and strictly complied with the ethical conditions by the Thailand Animal Welfare Act. Field work, including collection of animals in the field and specimen exportation was authorized by the Institute of Animals for Scientific Purpose Development (IAD), Bangkok, Thailand (permit number U1-01205-2558, issued to Chatmongkon Suwannapoom). 
The electronic version of this article in Portable Document Format (PDF) will

144

145

146

147

148

149

150

151

152

153

154

155

156

157

158

159

160

161

162

163

164

165

166

167

168

169

170

171

represent a published work according to the International Commission on Zoological Nomenclature (ICZN), and hence the new names contained in the electronic version are effectively published under that Code from the electronic edition alone (see Articles 8.58.6 of the Code). This published work and the nomenclatural acts it contains have been registered in ZooBank, the online registration system for the ICZN. The ZooBank LSIDs (Life Science Identifiers) can be resolved and the associated information viewed through any standard web browser by appending the LSID to the prefix http://zoobank.org/. The LSID for this publication is: urn:lsid:zoobank.org:pub:C8BD1C1D-0553-4662-8DE54337CD69E3B9. The online version of this work is archived and available from the following digital repositories: PeerJ, PubMed Central and CLOCKSS.

\section{Laboratory methods}

For molecular phylogenetic analysis, total genomic DNA was extracted from ethanol-preserved femoral muscle tissue using standard phenol-chloroform-proteinase $\mathrm{K}$ (final concentration $1 \mathrm{mg} / \mathrm{ml}$ ) extraction procedures with subsequent isopropanol precipitation (protocols in accordance with Hillis et al., 1996 and Sambrook \& David, 2001). The isolated full-genome DNA was visualized using agarose electrophoresis in presence of ethidium bromide. The total concentration of DNA in $1 \mu 1$ was measured using NanoDrop 2000 (Thermo Scientific), and consequently adjusted to ca. $100 \mathrm{ng}$ $\mathrm{DNA} / \mu \mathrm{L}$.

We amplified mtDNA fragments, covering partial sequences of 12S rRNA and 16S rRNA mtDNA genes and a complete sequence of tRNAVal mtDNA gene in order to obtain a 2591 bp-length continuous fragment of mtDNA. 16S rRNA is a molecular marker widely applied for biodiversity surveys in amphibians (Vences et al., 2005a, 2005b; Vieites et al., 2009). Together with 12S rRNA partial sequences these mtDNA markers were used in the most comprehensive phylogenetic studies on Microhylinae frogs published to date (Matsui et al., 2011; Pyron \& Wiens, 2011; de Sá et al., 2012; Peloso et al., 2015 and references therein), including the molecular taxonomic research on the subfamily Asterophryinae (Hoskin, 2004; Frost et al., 2006; Köhler \& Günther, 
172 2008; Günther et al., 2010; Kurabayashi et al., 2011; Rittmeyer et al., 2012; Blackburn et 173 al., 2013; Oliver et al., 2013, 2017b). Amplification was performed in $20 \mu 1$ reactions 174 using ca. $50 \mathrm{ng}$ genomic DNA, $10 \mathrm{nmol}$ of each primer, $15 \mathrm{nmol}$ of each dNTP, $50 \mathrm{nmol}$ 175 of additional $\mathrm{MgCl}_{2}$, Taq PCR buffer (10 mM of Tris- $\mathrm{HCl}$, $\mathrm{pH} 8.3,50 \mathrm{mM}$ of $\mathrm{KCl}, 1.1$ $176 \mathrm{mM}$ of $\mathrm{MgCl}_{2}$ and $0.01 \%$ gelatine) and $1 \mathrm{U}$ of Taq DNA polymerase. Primers used in

177 PCR and sequencing are summarized in Table 1. The PCR conditions included the 178 following steps: initial denaturation $-5 \mathrm{~min}$ at $94^{\circ} \mathrm{C}, 43$ cycles of denaturation $-1 \mathrm{~min}$ at $17994^{\circ} \mathrm{C}$, primer annealing -1 min with TouchDown program - reducing the temperature 180 from 65 to $55^{\circ} \mathrm{C}$ by 1 degree Celcius every cycle, extension -1 min at $72{ }^{\circ} \mathrm{C}$, and final 181 extension $-5 \mathrm{~min}$ at $72^{\circ} \mathrm{C}$.

PCR products were visualized using 1.5\% agarose electrophoresis in presence of ethidium bromide. If distinct bands were obtained, products were purified prior to cycle sequencing using $2 \mu \mathrm{l}$ of ExoSapIt (Amersham), diluted in the ratio 1:4, per $5 \mu \mathrm{l}$ of PCR product. A $10 \mu \mathrm{l}$ sequencing reaction included $2 \mu \mathrm{L}$ of template, $2.5 \mu \mathrm{l}$ of sequencing buffer, $0.8 \mu \mathrm{l}$ of 10 pmol primer, $0.4 \mu \mathrm{l}$ of BigDye Terminator version 3.1 Sequencing Standard (Applied Biosystems) and $4.2 \mu \mathrm{l}$ of water. The cycle sequencing reaction included 35 cycles consisting of the following steps: $10 \mathrm{sec}$ at $96^{\circ} \mathrm{C}, 10 \mathrm{sec}$ at $50^{\circ} \mathrm{C}$ and 4 $\min$ at $60^{\circ} \mathrm{C}$. Cycle sequencing products were purified by ethanol precipitation. Sequence data collection and visualization was performed on an ABI 3730xl automated sequencer (Applied Biosystems). The obtained sequences were deposited in the GenBank under the accession numbers MG682553-MG682559 (Table 2).

\section{Phylogenetic analyses}

For phylogenetic analyses we used the 12S rRNA and 16S rRNA Microhylidae dataset of Matsui et al. (2011) with addition of available sequences from other Microhylidae genera that are distributed in Southeast Asia and Australasia together with the newly obtained sequences of Microhylidae Gen. sp. from Kanchanaburi Province of Thailand. Data on sequences and specimens used in molecular analyses is summarized in Table 2. In total, sequences of the 12S rRNA and 16S rRNA mtDNA fragments of 56 microhylid representatives and one non-microhylid outgroup taxon were subjected to the 
201 final analyses, including seven samples of Microhylidae Gen. sp. from Kanchanaburi

202 Province and 44 samples of Asian and Australasian microhylids representing all major

203 lineages of the family inhabiting this region. The subfamily Asterophryinae was

204 represented by approximately 26 species belonging to the following genera:

205 Aphantophryne Fry, Asterophrys Tschudi, Austrochaperina Fry, Barygenys Parker,

206 Callulops Boulenger, Choerophryne Van Kampen, Cophixalus Boettger, Copiula

207 Méhely, Gastrophrynoides, Genyophryne Boulenger (now treated as a junior synonym of

208 Sphenophryne Peters \& Doria according to Rivera et al., 2017), Hylophorbus Macleay,

209 Liophryne Boulenger (included in the genus Sphenophryne by Rivera et al., 2017),

210 Mantophryne Boulenger, Metamagnusia Günther (treated as a junior synonym of

211 Asterophrys by Rivera et al., 2017), Oninia Günther, Stelbrink \& von Rintelen,

212 Oreophryne, Oxydactyla Van Kampen (considered as synonym of Sphenophryne by

213 Rivera et al., 2017), Paedophryne Kraus, Pseudocallulops Günther (included in the genus

214 Asterophrys by Rivera et al., 2017), Sphenophryne and Xenorhina Peters. Other

215 subfamilies included Microhylinae represented by genera Glyphoglossus Gunther,

216 Kaloula Gray, Metaphrynella Parker, Microhyla Tschudi, Micryletta Dubois, Phrynella

217 Boulenger and Uperodon Duméril \& Bibron (14 species in total), Kalophryninae with a

218 single genus Kalophrynus Tschudi (two species), Melanobatrachinae with a single

219 monotypic genus Melanobatrachus Beddome, and Chaperininae with a single monotypic

220 genus Chaperina Mocquard. Five outgroup sequences of non-Asian Microhylidae

221 included: Dyscophinae (genus Dyscophus Grandidier; two species), Gastrophryninae

222 (genus Gastrophryne Fitzinger; one species), Phrynomerinae (genus Phrynomantis

223 Peters; one species), Scaphiophryninae (genus Scaphiophryne Boulenger; one species)

224 subfamilies. MtDNA sequence of Rhacophorus schlegelii (Günther) (Rhacophoridae;

225 Sano et al., 2005) was used as a non-microhylid outgroup.

226 Nucleotide sequences were initially aligned using ClustalX 1.81 software

227 (Thompson et al., 1997) with default parameters, and then optimized manually in BioEdit

228 7.0.5.2 (Hall, 1999) and MEGA 6.0 (Tamura et al., 2013). Mean uncorrected genetic

229 distances ( $p$-distances) between sequences were determined using MEGA 6.0. 
230 MODELTEST v.3.06 (Posada \& Crandall, 1998) was applied to estimate the optimal

231 evolutionary models to be used for the data set analysis. The best-fitting model was

232 determined to be the $(\mathrm{GTR}+\mathrm{I}+\mathrm{G})$ model of DNA evolution, as suggested by the Akaike

233 Information Criterion (AIC). Both $12 \mathrm{~S}$ and 16S rRNA gene fragments were treated as a

234 single partition due to the relatively short sequence length and similar features (i.e., 235 mitochondrial rRNA).

236 Phylogenetic trees were inferred using two different methods: Maximum 237 Likelihood (ML) and Bayesian Inference (BI). The ML analysis was conducted using 238 Treefinder (Jobb et al., 2004). Confidence in tree topology was evaluated by non239 parametric bootstrap analysis (BS) with 1000 replicates (Felsenstein, 1985). The BI 240 analysis was conducted using MrBayes 3.1.2 (Huelsenbeck \& Ronquist, 2001; Ronquist 241 \& Huelsenbeck, 2003); Metropolis-coupled Markov chain Monte Carlo (MCMCMC) 242 analyses were run with one cold chain and three heated chains for four million 243 generations and were sampled every 1,000 generations. Five independent MCMCMC 244 runs were performed and 1,000 trees were discarded as burn-in. Confidence in the tree 245 topology was assessed using posterior probability (PP) (Huelsenbeck \& Ronquist, 2001). 246 We a priori regarded tree nodes with bootstrap (BS) values of $75 \%$ or greater and posterior probabilities (PP) values over 0.95 as sufficiently resolved, those with BS 248 values in the range between $75 \%$ and $50 \%$ (PP between 0.95 and 0.90 ) were regarded as tendencies, those with BS below 50\% (PP below 0.90) were considered to be unresolved (Huelsenbeck \& Hillis, 1993).

\section{Adult morphology}

Sex of adult individuals was determined using gonadal dissection. All measurements were taken to the nearest $0.02 \mathrm{~mm}$ (and subsequently rounded to a $0.1 \mathrm{~mm}$ precision) from preserved specimens using digital calliper under a light dissecting microscope; morphometrics were acquired according to Poyarkov et al. (2014): (1) snout-vent length (SVL; measured from the tip of the snout to cloaca); (2) head length

257 (HL; measured from the tip of snout to hind border of jaw angle); (3) snout length (SL; measured from the anterior corner of eye to the tip of snout); (4) eye length (EL; 
259 measured as the distance between anterior and posterior corners of the eye); (5) nostril260 eye length (N-EL; measured as the distance between the anterior corner of the eye and 261 the nostril center); (6) head width (HW; measured as the maximum width of head on the 262 level of mouth angles in ventral view); (7) internarial distance (IND; measured as the 263 distance between the central points of nostrils); (8) interorbital distance (IOD; measured 264 as the shortest distance between the medial edges of eyeballs in dorsal view); (9) upper 265 eyelid width (UEW; measured as the maximum distance between the medial edge of 266 eyeball and the lateral edge of upper eyelid); (10) forelimb length (FLL; measured as the 267 length of straightened forelimb to the tip of third finger); (11) lower arm and hand length 268 (LAL; measured as the distance between elbow and the tip of third finger); (12) hand 269 length (HAL; measured as the distance between the proximal end of outer palmar 270 (metacarpal) tubercle and the tip of third finger); (13) inner palmar tubercle length (IPTL; 271 measured as the maximum distance between proximal and distal ends of inner palmar 272 tubercle); (14) outer palmar tubercle length (OPTL; measured as the maximum diameter 273 of outer palmar tubercle); (15) hindlimb length (HLL; measured as the length of 274 straightened hindlimb from groin to the tip of fourth toe); (16) tibia length (TL; measured 275 as the distance between the knee and tibiotarsal articulation); (17) foot length (FL; 276 measured as the distance between the distal end of tibia and the tip of fourth toe); (18) 277 inner metatarsal tubercle length (IMTL; measured as the maximum length of inner 278 metatarsal tubercle); (19) first toe length (1TOEL), measured as the distance between the 279 distal end of inner metatarsal tubercle and the tip of first toe; (20-23) second to fifth toe 280 lengths (measured as the outer lengths for toes II-IV, as the inner length for toe V; $2-$ 5TOEL); (24) first finger width (1FW), measured at the distal phalanx; (25-27) finger disk diameters (2-4FDW); (28-32) toe disk diameters (1-5TDW); (33-36) finger lengths (1-3FLO, 4FLI; for outer side (O) of the first, inner side (I) of the fourth, measured as the distance between the tip and the junction of the neighbouring finger); (37) Tympanum 285 length, measured as the maximum tympanum diameter (TMP); (38) Tympanum-eye 286 distance (TEY). Terminology for describing eye coloration in living individuals is in 
287 accordance with Glaw \& Vences (1997); subarticular tubercle formulas follow those of 288 Savage (1975).

The morphological characters for comparison and the data on their states in other

290

291

292

293

294

295

296

297

298

299

300

301

302

303

304

305

306

307

308

309

310

311

312

313

314

315

Microhylidae representatives were taken from the following studies: Burton (1986), Chan et al. (2009), Günther \& Richards (2016), Günther (2009, 2017), Günther et al. (2010, 2012a, 2012b, 2014, 2016), Köhler \& Günther (2008), Kraus \& Allison (2003), Kraus (2010, 2011, 2013a, 2013b, 2014, 2016, 2017), Menzies \& Tyler (1977), Parker (1934), Richards \& Iskandar (2000), Richards et al. (1992, 1994), Rittmeyer et al. (2012), Zweifel (1972, 2000), Zweifel et al. (2003).

\section{Larval morphology}

Morphological description of larval stages follows Poyarkov et al. $(2015,2017)$, and Vassilieva et al. $(2014,2017)$ and includes the following 16 measurements: total length (ToL); body length (BL); tail length (TaL); maximum body width (BW); maximum body height $(\mathrm{BH})$; maximum tail height $(\mathrm{TH})$; snout to vent length (SVL); snout to spiracle distance (SSp); maximum upper tail fin height (UF); maximum lower tail fin height (LF); internarial distance (IN); interpupilar distance (IP); rostro-narial distance (RN); naro-pupilar distance (NP); eye diameter (ED) and mouth width (MW). Tadpoles were staged according to the table of Gosner (1960).

\section{Osteology}

Micro-CT scanning protocols followed Scherz et al. (2016). Micro-CT scanning was conducted at the Petroleum Geology Department, Faculty of Geology, Lomonosov Moscow State University using a SkyScan 1172 desktop scanner (Bruker microCT, Kontich, Belgium) equipped with a Hamamatsu 10Mp digital camera. Specimen was mounted on a polystyrene baseplate and placed inside a hermetically closed polyethylene vessel. Scans were conducted with a resolution of $3.7 \mu \mathrm{m}$ at $100 \mathrm{keV}$ voltages and current of $100 \mathrm{~mA}$ with rotation step $0.2^{\circ}$ with the use of oversize mode in which 4 blocks of sub scan data were connected vertically to obtain a general tomogram. Data processing was performed using Skyscan software: NRecon (reconstruction) and CTan/CTVol (3D model producing and imaging). Osteological terminology follows Scherz et al. (2016) 
316 and Trueb (1968, 1973). Micro-CT does not render cartilage, cartilage structures were

317 therefore omitted from the osteological descriptions.

318

319

\section{Results}

320

\section{Sequence variation}

The studied 12S rRNA - 16S rRNA mtDNA fragment consisted of 2,591 sites:

1,070 sites were conserved and 1,394 sites were variable, 1,070 of which were found to

be parsimony-informative. Hypervariable regions with poor local alignment were

removed using Gblocks v0.91b (Castresana, 2000); of the original 1,556 aligned positions, 2,253 were retained in final analyses. The transition-transversion bias $(\mathrm{R})$ was estimated to be equal to 2.18. Nucleotide frequencies were $\mathrm{A}=34.23 \%, \mathrm{~T}=22.89 \%$, $\mathrm{C}=24.85 \%$, and $\mathrm{G}=18.04 \%$ (all data given only for the Microhylidae ingroup).

\section{Phylogenetic relationships}

Results of phylogenetic analyses are shown in Figure 2. Bayesian and Maximum Likelihood analyses yielded essentially similar topologies that slightly differed only in associations at several poorly supported basal nodes. We achieved high resolution of phylogenetic relationships among major lineages of the subfamily Asterophryinae, with several sufficiently resolved major nodes ( $\mathrm{PP}=1.0$; $\mathrm{BS}=100 \%$ : Fig. 2). However, phylogenetic relationships between the subfamilies of Microhylidae, or within the Austro-Papuan radiation of Asterophryinae were poorly resolved with low or insignificant levels of support ( $\mathrm{BPP}<0.95$; $\mathrm{BS}<75 \%$ ) for major basal nodes.

The general topology of the phylogenetic relationships of microhylid frogs resulting from our analyses is consistent with the results reported in recent studies by Matsui et al. (2011), Kurabayashi et al. (2012), Pyron \& Wiens (2011), de Sá et al. (2012), the mtDNA dataset of Peloso et al. (2015) and Rivera et al. (2017).

Asterophryinae generic taxonomy is currently in a state of flux; we use the taxonomy 342 proposed by Rivera et al. (2017), who synonymized genera Genyophryne, 
343 Metamagnusia, Pseudocallulops, Liophryne and Oxydactyla, but also provide traditional 344 generic affiliation for these groups in brackets (see Fig. 2).

345 The Bayesian inference tree (Fig. 2) suggests the following set of genealogical 346 relationships among the assessed microhylid taxa. Phylogenetic relationships among the 347 subfamilies of Microhylidae are essentially unresolved; monophyly of the Dyscophinae, 348 Kalophryninae and Asterophryinae subfamilies is well-supported (1.0/100; hereafter, the 349

350 node support values are given for BI PP/ML BS, respectively).

Asterophryinae consists of two major well-supported (1.0/100) reciprocally

351

352

353

354

355

356

357

358

359

360

361

362

363

364

365

366

367

368

369

370

371

monophyletic clades:

(1) Asterophryinae 1, or "core" Asterophryinae, includes all presently known genera of the subfamily that inhabit Australasia east of the Wallace line and the island of Bali (see line B1 on Fig. 1; range of Asterophryinae 1 is marked in red). Phylogenetic relationships among genera within the clade Asterophryinae 1 remain essentially unresolved (Fig. 2); they are discussed in more details in a multilocus study of Rivera et al. (2017).

(2) The second clade includes the genus Gastrophrynoides known to date only from Sundaland - peninsular Malaysia and Borneo (lineage Asterophryinae 2 on Fig. 2; range on Fig. 1 is marked in blue), and the newly discovered microhylid from Kanchanaburi Province in western Thailand (lineage Asterophryinae 3 on Fig. 2; locality on Fig. 1 is marked in green).

Thus, our phylogenetic analyses indicate that the newly discovered Microhylidae Gen. sp. from Kanchanaburi Province in western Thailand falls into the radiation of Asterophryinae sensu lato and is placed as a sister lineage to the genus Gastrophrynoides with high levels of node support.

\section{Genetic distances}

The uncorrected genetic $p$-distances between the 12S rRNA - 16S rRNA gene fragments among and within the studied Microhylidae genera are shown in the Table 3. The genetic differentiation between the Microhylidae Gen. sp. from Kanchanaburi Province and other Microhylidae genera vary from 14.8\% (genus Liophryne) to 20.6\% of 
372 substitutions (genus Barygenys). Genetic distance between the Microhylidae Gen. sp. 373 and its sister lineage Gastrophrynoides reaches $15.6 \%$ of substitutions. These values of 374 genetic divergence are high and correspond well to the genus level of differentiation 375 observed in other groups of Anura (Vences et al., 2005a, 2005b; Vieites et al., 2009). No 376 genetic variation was recorded in obtained haplotypes of 12S rRNA-16S rRNA gene of 377 the new species (Table 3).

378

379

380

381

382

383

384

385

386

387

388

389

390

391

392

393

394

395

396

397

398

399

400

\section{Taxonomy}

Based upon the results of phylogenetic analyses of 12S rRNA - 16S rRNA mtDNA fragment sequences, the Microhylidae frog from Kanchanaburi Province represents a previously unknown highly divergent mtDNA lineage, clearly distinct from all other members of Microhylidae for which comparable genetic data were available. This lineage falls into the Australasian subfamily Asterophryinae and with high values of node support is reconstructed as a sister group to the genus Gastrophrynoides that inhabits Borneo and the peninsular Malaysia. Subsequent analyses of osteology and external morphology (see below) clearly indicate that the recently discovered population of Microhylidae Gen. sp. from Kanchanaburi Province represents a new previously undescribed genus and species which we describe herein as:

\section{Amphibia Linnaeus, 1758}

Anura Fischer von Waldheim, 1813

Microhylidae Günther, 1858

Asterophryinae Günther, 1858

\section{Siamophryne Gen. nov.}

Diagnosis. A medium-sized $(19 \mathrm{~mm}<\mathrm{SVL}<30 \mathrm{~mm})$ member of the Australasian subfamily Asterophryinae (family Microhylidae), with the following combination of morphological attributes: (1) both maxillae and dentaries eleutherognathine, no maxillary teeth; (2) vertebral column procoelous with 8 presacral vertebrae lacking neural crests; (3) no sagittal crest on cranium; (4) frontoparietals conjoined, connected by long suture; 
401 (5) nasals wide, calcified, but not contacting each other medially; (6) vomero-palatines 402 small, not expanded, vomerine spikes absent; (7) cultriform process of parasphenoid 403 comparatively narrow; (8) clavicles present as slender tiny bones, lying on the 404 procoracoid cartilage not reaching scapula or the midline; (9) omosternum absent; (10) 405 sternum large, anterior portion consists of calcified cartilage, xiphisternum cartilaginous; 406 (11) weak dorsal crest present on urostyle, absent on ilium; (12) terminal phalanges large 407 T-shaped; (13) all fingers and toe discs with terminal grooves; (14) subarticular tubercles 408 weak, discernible only at digit basis; (15) toe webbing absent; (16) tympanum distinct; 409 (17) two transverse smooth palatal folds; (18) pupil round; (19) snout rounded, equal to 410 eye length; (20) development with a larval stage, tadpole with peculiar dorso-ventrally 411 compressed morphology.

Type species. Siamophryne troglodytes sp. nov.

Other included species. None are known at present.

Distribution. To date, Siamophryne troglodytes sp. nov. is only known from a 415 small cave system in a karst region of Sai Yok District, Kanchanaburi Province, northern Tenasserim Region, western Thailand (see below the description of the species) (see Fig. 417 1).

Discrimination from other Asterophryinae genera. Information on character states for other Asterophryinae genera is based on Parker (1934), Zweifel (1972, 2000), Menzies \& Tyler (1977), Burton (1986), Zweifel et al. (2003), Günther et al. (2010), Kraus $(2010,2017)$ and references therein. The new genus has eleutherognathine maxillae and dentaries and thereby is distinguished from those Asterophryinae genera which have symphignathine state of this trait in both jaws: Asterophrys (including the recently synonymized Pseudocallulops and Metamagnusia; see Rivera et al., 2017) (New

425 Guinea), Callulops (from Sulawesi to New Guinea region), Mantophryne (New Guinea and Louisiade Archipelago), Oninia (New Guinea) and Xenorhina (including the recently synonymised Xenobatrachus Peters \& Doria) (New Guinea region). The genus Barygenys (Papua New Guinea region) can be distinguished from the new genus by the presence of symphignathine dentaries and eleutherognathine maxillae (versus both jaws 
430 being eleutherognathine in Siamophryne Gen. nov.). The new genus lacks distinct neural 431 crests on presacral vertebrae, and therefore can be differentiated from the genera 432 Aphantophryne (from Philippines to New Guinea) and Cophixalus (from Moluccas to 433 New Guinea and northern Australia) (both have well-developed neural crests on presacral 434 vertebrae); the new genus can be further distinguished from Aphantophryne as it has 8 435 presacral vertebrae (vs. 7 presacral vertebrae in Aphantophryne). The genus 436 Sphenophryne sensu lato (New Guinea) has well-developed long and slender clavicles 437 (vs. tiny clavicles that do not reach scapula and the midline in the new genus), and broad 438 vomero-palatines that contact each other medially, with a post-choanal portion overlying 439 the palatine region (vs. vomero-palatines not expanded in the new genus); Sphenophryne 440 sensu stricto (S. cornuta Peters \& Doria) can be further distinguished by a characteristic 441 spine-like projection on the upper eyelid (vs. smooth upper eyelid in the new genus), it also has arboreal life style (vs. troglophilous life style of the new genus). The genus Genyophryne (recently considered as a synonym of Sphenophryne; see Rivera et al., 444 2017) can be distinguished from the new genus by absence of clavicles (vs. clavicles present), stout body habitus (vs. slender body habitus) and absence of large finger discs (vs. very large finger discs in the new genus). The genus Liophryne (which is also regarded as a member of Sphenophryne sensu lato based on phylogenetic data of Rivera et al., 2017) can be differentiated from the new genus by the presence of long and slender clavicles (vs. tiny clavicles in the new genus), and by the presence of comparatively small finger discs (vs. large broad fingers discs in the new genus). The genus Oxydactyla (now regarded as a part of Sphenophryne sensu lato; see Rivera et al., 2017) can be distinguished from the new genus by the absence of finger discs (vs. large finger discs present in the new genus). The genus Paedophryne (New Guinea region) can be distinguished from the new genus by a much smaller body size $(\mathrm{SVL}<20 \mathrm{~mm}$, vs. $\mathrm{SVL} \geq 20 \mathrm{~mm}$ in the new genus), by cartilaginous phalanges in the first digit (vs. ossified 456 phalanges in the new genus), by FI reduced to a nub (vs. well-developed FI in the new 457 genus), by the absence of clavicles and procoracoids (vs. presence in the new genus) and 
459 presence of clavicles and procoracoid cartilage, the new genus can be differentiated from 460 the genus Choerophryne (New Guinea), which lacks these structures; the latter also has 461 palatine portions of vomero-palatines fused with broad sphenethmoids (vs. not fused in 462 the new genus). The genus Copiula (New Guinea) can be distinguished from the new 463 genus by the lack of clavicles (vs. presence in the new genus), by small discs on fingers, 464 which are smaller than those on toes (vs. large finger discs that are larger than toe discs in 465 the new genus), by cartilaginous sternum (vs. ossified anterior portion of sternum in the 466 new genus), and by the presence of a conspicuous rostral dermal gland (vs. rostral gland 467 absent in the new genus). The new genus can be distinguished from Austrochaperina 468 (Australia, New Guinea and New Britain) by fingers with very wide discs, much wider 469 than penultimate phalanges, by vomero-palatines not expanded and by narrow cultriform 470 process of parasphenoid (vs. discs on fingers absent or small, slightly different in width

471 from penultimate phalanges, vomero-palatines expanded and broad cultriform process of 472 parasphenoid in Austrochaperina). The new genus can be distinguished from 473 Hylophorbus (New Guinea) by comparatively better developed nasals (vs. poorly 474 developed nasals in Hylophorbus), by the presence of large finger discs (vs. discs on 475 fingers usually absent, if present, they are much smaller than toe discs) and by completely 476 smooth skin on dorsum (vs. shagreened to tubercular skin on dorsum in Hylophorbus).

477 The genus Oreophryne (from Philippines and Lesser Sundas to New Guinea and New 478 Britain, see Kraus, 2017) can be differentiated from the new genus by distinct toe 479 webbing (vs. no toe webbing in the new genus), by arboreal or terrestrial life style (vs. 480 troglophilous life style in the new genus), and by expanded vomero-palatines (vs. not 481 expanded in the new genus).

From its sister genus Gastrophrynoides (peninsular Malaysia and Borneo) the new 483 genus can be easily distinguished by the presence of large and wide finger discs (vs. 484 small finger discs, slightly wider than the penultimate phalanges in Gastrophrynoides), 485 by a comparatively much shorter snout and larger eye (snout length equal to eye length in 486 the new genus vs. snout 2.5 times longer than eye in Gastrophrynoides) and by a distinct 487 tympanum (vs. tympanum obscured by skin in Gastrophrynoides). 
Finally, the sequences of the $12 \mathrm{~S}-16 \mathrm{~S}$ rRNA mtDNA fragment for the new genus

489

490

491

492

493

494

495

496

497

498

499

500

501

502

503

504

505

506

507

508

509

510

511

512

513

514

515

516

\section{2}

are markedly distinct from the sequences for all those Microhylidae members, for which homologous sequences are available (see Fig. 2, Table 3).

Etymology. The generic nomen Siamophryne is derived from "Siam" - the old name of present-day Thailand; referring to the range of the new genus, which to date is only known from western Thailand; and the Greek noun "phryne" ( $\varphi \rho v ́ v \eta$; feminine gender), meaning "toad" in English; this root is often used in the generic names in Asterophryinae microhylid frogs. Gender of the new genus is feminine.

\section{Siamophryne troglodytes sp. nov.}

Figs. 3-10; Table 4.

Holotype: AUP-00500, adult male in a good state of preservation, collected in a limestone cave in Sai Yok District, Kanchanaburi Province, western Thailand, elevation $440 \mathrm{~m}$ a.s.1. (approximately in the vicinity of $14^{\circ} 28^{\prime} \mathrm{N}, 98^{\circ} 51^{\prime} \mathrm{E}$; exact geographic coordinates not provided for conservation purposes) (see Fig. 10); collected on October 27, 2016, by Montri Sumontha, Jitthep Tunprasert, Niruth Chomngam, and Chatmongkon Suwannapoom.

Paratypes: In total, 10 specimens: AUP-00501-00504, four adult males, and AUP-00505-00508, three adult females, collected on October 27, 2016, from the same locality and with the same data as the holotype; ZMMU A-5818 (field ID NAP-06651), adult male, and ZMMU A-5819 (field ID NAP-06652), adult female, collected by T. Ruangsuwan from the same locality as the holotype on August 1, 2016.

Referred specimens: AUP-00509, a larval specimen, Gosner stage 36, collected by T. Ruangsuwan from the same locality as the holotype on August 1, 2016.

Diagnosis: The only known member of the genus Siamophryne Gen. nov. (see Diagnosis of the genus). Siamophryne troglodytes sp. nov. is characterized by a combination of the following traits: (1) snout-vent length of six adult males $19.1 \mathrm{~mm}$ to $24.9 \mathrm{~mm}$, and of five adult females $25.0 \mathrm{~mm}$ to $27.8 \mathrm{~mm}$; (2) body habitus slender, limbs very long (FLL/SVL ratio $0.69(0.65-0.74)$; HLL/SVL 1.50 ratio (1.39-1.67) for both 
517 sexes); (3) snout short, rounded, subequal to eye length (0.8-1.0 times the length of the 518 eye); (4) eye medium-sized, eye length/ snout-vent length ratio - 0.12 to 0.14 ; (5) tips of 519 fingers II-IV expand to broad discs 1.5-2.5 times wider than the penultimate phalanges;

520 toes II-IV with smaller discs slightly wider than the penultimate phalanges, tips of finger

521 I, toe I and toe V rounded, same width as the penultimate phalanges; (6) finger discs 522 distinctly wider than toe discs; (7) terminal phalanges distinctly T-shaped in F2-F4 and

523 T2-T5; bobbin-shaped in finger I and toe I; (8) subarticular tubercles on fingers weak, 524 indistinct; finger subarticular tubercle formula: 1:1:1:1; better pronounced on toes, toe 525 subarticular tubercle formula: 1:1:1:1:1; (9) outer metatarsal tubercle absent, inner 526 metatarsal tubercle small, rounded; (10) skin of the ventral surface completely smooth, 527 skin of the dorsal and lateral surfaces smooth with rare flat tubercles or pustules; (11) 528 osteological features are the same as for the genus. Other diagnostic features are given in 529 the diagnosis of the genus.

530 Description of the holotype. Holotype in preservative is shown in Fig. 3 and Fig. 4. Medium-sized specimen, with SVL 22.1 (hereafter all measurements in $\mathrm{mm}$ ), in a good 532 state of preservation, however distal parts of toes II-V slightly dehydrated (Fig. 3 E); ventral surface of left thigh dissected for $5 \mathrm{~mm}$ and some of femoral muscles removed. Body habitus slender (Fig. 3 A); head length slightly shorter than head width (HL/HW 0.95); snout rounded both in profile (Fig. 3 C; Fig. 4 A) and in dorsal view (Fig. 3 A), shorter than the diameter of eye (SL/EL 0.91); eyes large, notably protuberant in dorsal and lateral views, pupil oval, horizontal (Fig. 3 C); dorsal surface of head flat, canthus rostralis indistinct, gently rounded; loreal region weakly concave; nostril rounded, lateral, located much closer to tip of snout than to eye; tympanum well discernable, circular, tympanic rim not elevated above the skin of temporal area, supratympanic fold absent; vomerine teeth absent, two transverse palatal folds present across the palate anteriorly to the pharynx, both of them with smooth edges, tongue spatulate and free behind, lacking papillae, vocal sac opening not discernable. 
$544 \quad$ Forelimbs comparatively long, less than half length of hindlimbs (FLL/HLL 0.42);

545 hand slightly longer than lower arm and less than half length of forelimb (HAL/FLL

546 0.36); fingers slender, flattened in cross-section, first finger well developed, one half

547 length of the second finger ( $1 \mathrm{FLO} / 2 \mathrm{FLO} 0.50$ ); relative finger lengths: $\mathrm{I}<\mathrm{II}<\mathrm{IV}<\mathrm{III}$ (see

548 Fig. 3 D, Fig. 4 B). Finger webbing and dermal fringes absent. First fingertip rounded and

549 slightly dilated, almost the same width as the basal phalanx. Tips of three outer fingers

550 II-IV greatly dilated forming large triangular disks with distinct narrow terminal grooves;

551 relative finger disk widths: $\mathrm{II}<\mathrm{IV}<\mathrm{III}$; longitudinal furrow on the dorsal surface of fingers

552 absent; flexor tendons visible through translucent skin on ventral surface of fingers;

553 subarticular tubercles on fingers barely distinct at basis of proximal phalanges and almost

554 indistinct under penultimate phalanges of fingers III and IV, subarticular tubercles flat,

555 oval-shaped with unclear borders, finger subarticular tubercle formula: 1:1:1:1 (for

556 fingers I:II:III:IV, respectively); nuptial pad absent; two palmar (metacarpal) tubercles:

557 inner palmar tubercle small, rounded, same size as subarticular tubercles; outer palmar

558 tubercle oval-shaped with indistinct borders, almost the same length as inner palmar

559 tubercle (IPTL/OPTL 0.97); palmar surface smooth, supernumerary palmar tubercles 560 absent.

561 Hindlimbs long and slender, tibia length is half of snout-vent length (TL/SVL 562 0.49); tibiotarsal articulation of adpressed limb reaching the eye level; foot shorter than 563 tibia (FL/TL 0.89); relative toe lengths $\mathrm{I}<\mathrm{II}<\mathrm{V}<\mathrm{III}<\mathrm{IV}$; tarsus smooth, tarsal fold absent;

564 tips of all toes slightly dilated forming small spatulate disks on all toes except toe I (Fig. 5653 E, Fig. 4 C), each disk with weak terminal groove similar to that on fingers, relative toe 566 disk widths: $\mathrm{I}<\mathrm{II}<\mathrm{V}<\mathrm{III}<\mathrm{IV}$; toes slightly flattened in cross-section, dermal fringes 567 absent; toe webbing absent between all toes; subarticular tubercles on toes more distinct 568 than on fingers, oval-shaped, elevated, toe subarticular tubercle formula: 1:1:1:1:1 (for 569 toes I:II:III:IV:V, respectively); single metatarsal tubercle: inner metatarsal tubercle 570 rounded, flattened.

571 Skin on dorsal and dorsolateral surfaces smooth with rarely scattered flat tubercles

572 (Fig. 3 A), tubercles getting larger and more prominent on dorsal surfaces of hindlimbs; 
573 dorsal surface of forelimbs smooth with few small tubercles on forearm; upper eyelids

574 smooth; ventral sides of trunk, head and limbs completely smooth (Fig. 3 B); dermal

575 ridges or skin macroglands absent.

576 Measurements of holotype (in mm). SVL 22.1; HL 6.7; SL 2.7; EL 3.0; N-EL

577 1.9; HW 7.1; IND 2.3; IOD 2.2; UEW 1.8; FLL 15.4; LAL 10.4; HAL 5.6; IPTL 1.0;

578 OPTL 1.1; HLL 37.1; TL 10.8; FL 9.6; IMTL 0.9; 1TOEL 2.0; 2TOEL 4.7; 3TOEL 7.4;

579 4TOEL 9.6; 5TOEL 7.3; 1FW 1.0; 2FDW 1.2; 3FDW 1.3; 4FDW 1.3; 1TDW 0.2;

580 2TDW 0.2; 3TDW 0.3; 4TDW 0.5; 5TDW 0.3; 1FLO 1.9; 2FLO 3.7; 3FLO 5.6; 4FLI

581 4.5; TMP 1.2; TEY 0.8 .

582 Coloration of holotype in life. Coloration rather uniform: dorsal surface of head 583 and trunk chocolate brown; dorsal surface of limbs ochre-brown; ventral surface of limbs 584 and throat light orange-pink, lateral sides of body grey to grey-brown; ventral surfaces of 585 body pinkish-grey. Fingers and toes grey with dark brown mottling. Tympanum greyish 586 with slight brown mottling. Tubercles on dorsal surfaces of body, limbs and head copper587 brown. Iris uniform dark brown; pupil black; sclera bluish-grey.

588 Coloration of holotype in preservative. Coloration in preservative is shown on 589 Fig. 3. After preservation in ethanol, dorsal coloration changed to greyish-brown, upper 590 eyelids dark-grey (Fig. 3 A), ventral surface of chest, belly, limbs turn yellowish-grey 591 (Fig. 3 B); iris coloration faded and turned black.

Morphological variation of the type series. Measurements of the type series that 593 show variation in morphometric characteristics are given in Table 4. Coloration of 594 paratype in life is shown in Fig. 5. Specimens show no significant variation in coloration.

595

596

597

598

599

600

601 Specimens vary in the body size: females (SVL 25.0-27.8; mean 26.3 $\pm 0.7 ; n=5$ ) are larger than males (SVL 19.1-24.9; mean 22.4 $\pm 2.1 ; \mathrm{n}=6$ ). Paratypes in situ had generally darker coloration with dark grey-brown coloration of dorsum and grey coloration of ventral surfaces and body flanks (Fig. $10 \mathrm{C}, \mathrm{D}$ ).

Osteological characteristics. Based on microtomographic data from ZMMU A5818, adult male. The main skeletal features are shown in Figure 6. Details of skull morphology are presented in Figure 7. 
Skull clearly longer than wide (Fig. 6). Frontoparietals separate along their entire 603 length, longer than broad, narrower anteriorly than posteriorly, connected with each other 604 medially with long suture, lack a sagittal crest, partially fused to exoccipital posteriorly 605 (Fig. 7 A). Exoccipitals separate, contact each other medially. Nasals large but not 606 meeting each other at midline, lacking posterior ramus, chondrified peripherally, 607 overlying the dorsal portion of sphenethmoid (Fig. 7 A). Sphenethmoid ossified laterally 608 and dorsally, but chondrified anteriorly and ventrally (Fig. 7 B). Prootics partially 609 chondrified, lacking dorsal crest (Fig. 7 C). Squamosal L-shaped, well-ossified, distally 610 chondrified, articulating on anterolateral surface of prootic (Fig. 7 C). Columella 611 comparatively small, centrally ossified (Fig. 7 C), distally chondrified; tympanic annulus completely chondrified. Premaxilla with slender, weakly mineralized dorsal process; labial process of premaxilla well-ossified (Fig. 7 D). Maxilla largely chondrified, ossified in central part. Anterior ends of maxillaries contact labial portions of well-developed premaxillaries (eleutherognathine condition) (Fig. 7 D). Quadratojugal ossified in posterior portion. Vomers mostly chondrified plates meeting at midline, without teeth or lateral processes; parts edging choanae weakly ossified (Fig. 7 C). Mentomeckelians ossified, connected to dentaries and to each other by strips of cartilage (Fig. 7 B); dentaries not fused (eleutherognathine condition). Parasphenoid smooth; cultriform process of parasphenoid rather narrow, terminates at the level of sphenethmoid with an anterior notch (Fig. 7 B). Hyoid plate completely cartilaginous, anterolateral (alary)

622 processes of hyoid plate present, recurved, posterolateral processes thinner than alary 623 processes; posteromedial processes strongly ossified, elongated, straight, wider at proximal ends, chondrified at distal ends (Fig. 6 B).

Eight nonimbricate procoelous presacral vertebrae (PSV), stout, length approximately from one-third to one half of width; presacral vertebrae longer anteriorly, narrowing progressively to the posterior; all except the first with wide diapophyses, 628 which are also longer anteriorly (3d PSV has the longest transverse processes), 629 decreasing in length progressively to the posterior, with chondrified tips (Fig. 6 A, B). 630 Diapophyses of vertebrae 2, 7 and 8 oriented anteriad, those of third and sixth - straight, 
631 and those of fourth and fifth oriented posteriad. Neural crests on PSV absent. Sacrum 632 with slightly expanded diapophyses. Urostyle with weak dorsal crest running along about $63375 \%$ of its shaft; ilia smooth, lacking dorsal crest (Fig. 6 A).

634 Coracoids, scapulae and suprascapulae present; first two fully ossified; 635 suprascapula largely chondrified. Coracoids robust with narrow distal ends oriented 636 anteriad; proximal ends greatly expanded (Fig. 6 B). Omosternum absent. Procoracoid 637 cartilage well-developed, extends from the scapula to the mid-line of the girdle. Clavicles 638 present as slender, tiny, slightly recurved bones, lying on the procoracoid cartilage, not 639 640 distale I small, carpale distale II-IV fused into a single large element, prepollex and a 643 large radiale lie between a small Y-element and an elongated ulnare. Metacarpals long 644 and fully ossified; phalangeal formula: 2-2-3-3; all phalanges ossified; distal phalanx of 645 finger I bobbin-shaped; terminal phalanges of fingers II-IV with greatly expanded, Tshaped tips, approximately 3-4 times wider than penultimate phalanges (Fig. 6 C, D). Foot (Fig. 6 E, F) with four tarsal elements, including ossified tarsale distale II-III, 648 central and a prehallux; prehallux ossified. Metatarsals fully ossified, long and relatively more massive than metacarpals; phalangeal formula: 2-2-3-4-3; all phalanges ossified 650 (Fig. $6 \mathrm{E}, \mathrm{F}$ ). Terminal phalanges of all toes with slightly expanded, T-shaped tips; equal 651 in width to penultimate phalanges on toes $\mathrm{I}$ and $\mathrm{V}$, slightly exceeding the width of 652 penultimate phalanges on toes II-IV (Fig. 6 E, F).

Larval morphology. Tadpole morphology description is based on a single larval specimen AUP-00509, Gosner stage 36, collected from the type locality. External 655 appearance and coloration of the tadpole in life is shown in Fig. 8; morphological details in preservative are presented in Fig. 9. Body measurements are given below.

The single encountered tadpole was attributed to Siamophryne troglodytes Gen. et 658 sp. nov. based on the following evidence: (1) morphological features characteristic for 659 Microhylidae larvae in general (flattened body, mouthparts lack lateral lobes and 
660 keratinized structures); (2) collected in a crevice in the limestone cave, where adult 661 animals were observed (see Fig. 10 E, F); (3) species identification confirmed by mtDNA 662 sequence of short $16 \mathrm{~S}$ rRNA gene fragment (up to $500 \mathrm{bp}$ ), identical to that of adult 663 specimens (GenBank Acession number: MG682559, see Table 2).

664 Standard tadpole measurements (AUP-00509, Gosner stage 36) (all in mm, taken 665 by TR): ToL: 35.1; BL: 12.1; TaL: 21.8; BW: 7.9; BH: 5.4; TH: 4.0; SVL: 13.6; SSp: 666 5.6; UF: 1.0; LF: 1.0; IN: 1.2; IP: 1.7; RN: 1.9; NP: 1.9; ED: 1.0; MW: 2.6 .

667 In dorsal view (Fig. 8 A, Fig. 9 B), body elongated (BW/BL 0.65) guitar-shaped 668 with large bluntly rounded anterior part and a distinct narrowing behind the eyes that 669 forms notably angular body edges; snout blunt with a shallow medial notch. From lateral 670 view (Fig. 9 A), both head and body strongly flattened. Tail strong, with well-developed 671 muscles, less than two times longer than the body (Tal/BL 1.80), tail width at tail basis 672 subequal to interorbital distance; tail tip gently rounded. Tail fins very low, with even 673 edges; dorsal fin not extending on the trunk, ventral fin same height as dorsal fin (LF/UF 674 0.94). A wide gular fold across the anterior half of body on the level of ca. 1/3 of body 675 length (Fig. 8 B, Fig. 9 B). Spiracle medial, narrow, slit-like, transversal; located in the 676 anterior half of body (SSp/SVL 0.41); covering membrane with even free margin. Vent 677 tube medial, oblique.

678 Eyes dorsal, very small (ED/BL 0.08); with dorsolateral orientation of pupils. Small 679 unpigmented narial protuberances present in nostril area. Mouth terminal, oriented 680 antero-ventrally, not visible from dorsal view (Fig. 9 B), mouth opening transverse, slit681 like from ventral view (Fig. 9 C), relatively wide (MW/BW 0.33). From lateral view (Fig. 6829 A), upper labium slightly projecting and overhanging over the mouth opening; upper 683 labium with even edge; lower labium short, with U-shaped edge. Protuberances in mouth 684 angles, lateral lobes and keratinized mouthparts absent. No papilla seen on mouth floor or 685 mouth roof. Lingual anlage rounded.

Coloration. In life at stage 36 larva almost unpigmented and in situ appears 687 translucent with dark-black colored eyes (Fig. 10 E, F). In laboratory conditions, live 688 tadpole (Fig. 8) shows semitransparent body with weak brownish pigmentation on dorsal 
689 surfaces of body and tail; a strongly-pigmented dark stripe runs along dorsal surface from 690 interorbital region to tail base (Fig. 8 A). Tail fins and ventral sides unpigmented, in life 691 this allows to see heart, liver and major blood vessels from ventral view (Fig. 8 B). Limb 692 buds pigmented with brown. In preservative, brown color fades to brown-grey (Fig. 9).

Natural history notes. Siamophryne troglodytes Gen. et sp. nov. has a 694 troglophilous life style and to date is only known from a small limestone cave system in 695 western Thailand. All specimens were collected within a narrow area inside a limestone 696 cave located on elevation $440 \mathrm{~m}$ a.s.l. in a polydominant tropical forest in Sai Yok 697 District, Kanchanaburi Province, western Thailand (Fig. 10 A). The cave was examined 698 twice on the 1st of August and the 27th of October, 2016. In both cases, adult specimens of Siamophryne troglodytes Gen. et sp. nov. were only recorded inside the cave, at a 700 distance of more than $25 \mathrm{~m}$ from the entrance, sitting on walls of the cave (Fig. $10 \mathrm{~B}, \mathrm{D}$ )

701

702 703 or hiding inside small caverns in limestone (Fig. 10 C) or under flat stones. Despite the thorough search, no animals were recorded near the cave entrance or in the forest close to the cave. Animals were active from 23:00 to 24:00, when the air temperature inside the cave was $28^{\circ} \mathrm{C}$ in August and $26^{\circ} \mathrm{C}$ in October, in both cases with $100 \%$ humidity. No calling activity was recorded during both surveys. Diet and enemies of the new frog are unknown.

Three tadpoles (one of which was collected) were observed during the survey on the 1st of August, 2016, in a small water-filled cavity in the limestone on the floor of the cave, ca. $10 \mathrm{~m}$ from the cave entrance (Fig. 10 E, F). The cavity was filled with water, the average depth was 4-5 cm; mosquito larvae (Chironomidae) were also observed in the same water body. Four other tadpoles (not collected) were discovered in another similar water-filled cavity inside the cave ( $30 \mathrm{~m}$ from the cave entrance).

The cave system where Siamophryne troglodytes Gen. et sp. nov. was discovered is inhabited by several species of bats which produce significant amount of guano that accumulates on the cave floor. According to a local guide, the locals mine this guano and that affects the ecosystem of the cave. 
Comparisons. As for the genus. Siamophryne troglodytes Gen. et sp. nov. is a

718

719

720

721

722

723

724

725

726

727

728

729

730

731

732

733

734

735

736

737

738

739

740

741

742

743

744

745 medium-sized frog $(19 \mathrm{~mm}<\mathrm{SVL}<30 \mathrm{~mm})$ and can be easily distinguished from all other microhylids inhabiting the mainland Southeast Asia by long limbs with digits bearing large disks, with those on fingers up to 2.5 times wider than the penultimate phalanges (vs. finger tips not expanded into prominent discs in Kalophrynus, Glyphoglossus, Microhyla and Micryletta); by the absence of tibiotarsal projection and uniform dullbrownish coloration of ventral surfaces (vs. the presence of bony tibiotarsal projection and belly with bright saffron-yellow spots in Chaperina); by single small subarticular tubercle with indistinct borders at the basis of each finger (vs. subarticular tubercles of the fingers greatly enlarged to form accessory adhesive organs in Phrynella and Metaphrynella); by the lack of a bony ridge along the posterior border of each choana (vs. well-developed bony ridge along the posterior border of each choana in Kaloula), by the presence of a distinct tympanum (vs. hidden tympanum in genera Glyphoglossus, Microhyla, Micryletta, Kaloula, Phrynella and Metaphrynella).

The new species can be further distinguished from Gastrophrynoides, another Asterophryinae genus inhabiting the mainland Southeast Asia, by slender body habitus (vs. body habitus robust in Gastrophrynoides, see Fig. 2 for details), by a short rounded snout, that is $0.8-1.0$ times the eye diameter (vs. long, pointed snout that is $2.6-3.0$ times the diameter of the eye in Gastrophrynoides) and by a well-developed tympanum (vs. tympanum hidden in Gastrophrynoides).

Distribution. As for the genus. At present, Siamophryne troglodytes Gen. et sp. nov. is known from a single limestone karst cave in Sai Yok District of Kanchanaburi Province in western Thailand. To date, numerous surveys in the nearby karst massifs have not yielded discoveries of additional populations of the new species. However, further fieldwork in Kanchanaburi Province of Thailand and the adjacent parts of Tanintharyi Division of Myanmar are required.

Conservation status. This species was unknown to science and even to local people for a surprisingly long time despite intense human activity in this region; that suggests a possibly very limited range. Despite our numerous attempts to find additional 
746 localities of the new species in adjacent limestone areas, we failed to detect other

747 populations of this troglophilous frog. In this regard, we consider a disclosure of the

748 detailed collecting locality information premature. In the case of narrow-ranged species

749 of amphibians, the locality information should be released only after effective

750 conservation measures have been taken and legal protection status have been established

751 (see discussion in Hou et al., 2014). Until then, this information can be requested from

752 the School of Agriculture and Natural Resources, University of Phayao. Currently, the

753 only known habitat of Siamophryne troglodytes Gen. et sp. nov. is endangered due to

754 illegal guano mining with the use of explosives, which is destroying the cave ecosystem.

755 Given the available information, we suggest Siamophryne troglodytes Gen. et sp. nov. to

756 be considered as an Endangered (EN) species following IUCN's Red List categories

757 (IUCN Standards and Petitions Subcommittee, 2016).

758 Etymology. The specific name "troglodytes" is a Latin adjective in the nominative

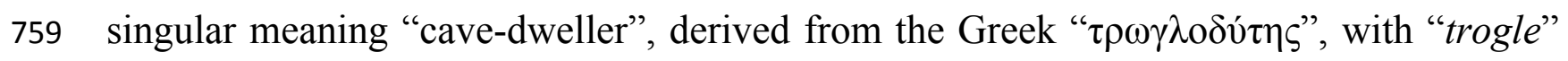
760 meaning "hole, mouse-hole" and "dyein" meaning "go in, dive in"; referring to the 761 troglophilous biology of the new species, which was recorded only in a limestone karst 762 cave system.

763 Suggested common names. We recommend the following common names for the 764 new species: "Tenasserim Cave Frog" (English); "Eung Tham Tenasserim" (Thai).

765

766

\section{Discussion}

767

768

769

from western Thailand, Tenasserim region of mainland Southeast Asia. As predicted by Kurabayashi et al. (2011), Siamophryne troglodytes represents an ancient lineage of Asterophryinae frogs distributed deep in the mainland Southeast Asia (Indo-Burma); it is reconstructed as a sister lineage to Gastrophrynoides - the only asterophryine found in the areas derived from the Eurasian landmass (Sundaland) until now. Our discovery of 
775 it documents the presence of Asterophryinae lineage north of the Isthmus of Kra (see Fig.

776 1) and thus strongly supports the Asian dispersal scenario for the group, suggested by 777 Kurabayashi et al. (2011). According to this scenario, the splitting of the lineage that 778 gave birth to the ancestors of Asterophryinae, Microhylinae and Dyscophinae occurred in 779 the Indian landmass during the late Cretaceous (around $70 \mathrm{Ma}$ ). Following the collision 780 of the India plate and the Eurasia during the Eocene (around $48 \mathrm{Ma}$, Kurabayashi et al., 781 2011), Asterophryinae common ancestor would have colonized mainland Southeast Asia 782 and split into Gastrophrynoides + Siamophryne lineage and the ancestor of the "core" 783 Asterophryinae 1 lineage. During the late Oligocene (around $25 \mathrm{Ma}$ ) the "core" 784 Asterophryinae 1 ancestorsfurther dispersed eastwards from mainland Asia to 785 Australasian landmass via islands and/or short sea straits, where they undergone a 786 comparatively recent and fast adaptive radiation following the orogenetic processes in the

787 Fold Belt and the Australian Craton of New Guinea (Rivera et al., 2017) and 788 subsequently colonized northern Australia and adjacent smaller islands.

Thus, our work demonstrates that Siamophryne troglodytes represents an old lineage of initial radiation of Asterophryinae sensu lato, which took place in the mainland Southeast Asia. The discovery of Siamophryne troglodytes goes in line with the biogeographic pattern reported for the Australasian frog family Ceratobatrachidae 793 (Natatanura) by Yan et al. (2016): until recently, this family was only known from the South-West Pacific to the island archipelagos of South Asia, with primary centers of species diversity in Philippines and Solomon-Bismarck Archipelago. However, a recent phylogenetic study greatly extended the westernmost border of geographic distribution of the primarily Australasian family Ceratobatrachidae into western Thailand (Tenasserim) and Himalaya and assigned early branching events in this family to the lineages that are now exclusively represented by the mainland species with ranges restricted to Himalaya 800 and Tibet (Yan et al., 2016). Hence, the biogeographic scenarios for at least two most 801 speciose frog families of the Australasia suggest that their origin and early cladogenesis 802 in the mainland Southeast Asia was followed by dispersal into Australasian archipelago 803 and subsequent radiation. Our study encourages further field research and phylogenetic 
804 studies on Southeast Asian frogs, since they may yield discoveries of new taxa and 805 unexpected biogeographic patterns.

\section{$806 \quad$ Natural history and reproductive biology}

807

Limestone caves provide unique combinations of ecological features, such as 808 rocky vertical substrates, climatic stability, low illumination, relaxed predation, and 809 reduced prey base. Cave-dwelling taxa of amphibians and reptiles are often characterized 810 by unique morphological adaptations, which are supposed to increase locomotion efficiency on vertical and inverted surfaces within cave-like microhabitats. In cavedwelling ecomorphs of Cyrtodactylus geckoes these often include comparatively shorter trunks; longer and thinner limbs; flatter, narrower, and sometimes longer heads; and relatively larger eyes (Grismer \& Grismer, 2017). Siamophryne troglodytes, as compared to its sister genus Gastrophrynoides, shows a number of morphological differences, which might be connected to its troglophilous life style. These include slender body habitus with notably longer limbs (see Fig. 2 for comparison), long and thin fingers and toes with tips expanded to large discs (see Fig. 5), slightly longer head (HL/SVL ratio $0.31(0.30-0.33 ; \mathrm{N}=11)$ in Siamophryne troglodytes vs. $0.28(0.27-0.29 ; \mathrm{N}=3)$ in Gastrophrynoides immaculatus), and comparatively larger eyes (EL/HL ratio 0.41 (0.37$0.46 ; \mathrm{N}=11)$ in Siamophryne troglodytes vs. $0.20(0.19-0.20 ; \mathrm{N}=3)$ in Gastrophrynoides immaculatus). Higher distances between the opposing hands and opposing feet with enlarged digit disks and larger eyes might facilitate locomotion on vertical and inverted walls of limestone caves in low illumination conditions.

The life cycle of many Asterophryinae species is still unknown and females of most species are rare in museum collections. For the Australo-Papuan "core" Asterophryinae lineage there is sufficient evidence that allows to assume that all of the members of that lineage have direct development - a life cycle with metamorphosis taking place within the egg (Menzies, 2006; Günther et al., 2012b); this contrasts sharply 830 with the Southeast Asian Microhylinae and Kalophryninae, all of which have free-living tadpoles. The reproductive biology and development of Gastrophrynoides is completely unknown (Parker, 1934; Chan et al., 2009); to our knowledge, no information on female 
833 or egg morphology in this genus is available either. Our work shows that Siamophryne 834 troglodytes possesses a life cycle with a free-living larval stage; tadpole morphology of 835 the new genus is very peculiar and was not reported for any other microhylid so far. This 836 is the first report of a free-living tadpole for Asterophryinae, as well as the first known 837 Asterophryinae with a troglophilous life style. Our description is based on a single larval 838 specimen, further studies on the reproductive biology and development of Siamophryne 839 troglodytes as well as of the genus Gastrophrynoides are required to understand the 840 details of life cycle in this lineage of Asterophryinae. It is assumed that the divergence 841 between the "core" Asterophryinae lineage and the Siamophryne + Gastrophrynoides 842 lineage took place no later than the Eocene (Kurabayashi et al., 2011). Further research 843 might reveal more significant differences in morphology and natural history of these 844 lineages.

\section{$845 \quad$ Conservation}

Our study adds a new genus of frogs to the batrachofauna of Thailand and 847 Indochina; according to our knowledge, Siamophryne troglodytes is endemic to a small limestone cave system in Sai Yok District of Kanchanaburi Province in western Thailand. This small area is known for an exceptionally high number of endemic species of squamates discovered by previous herpetofaunal surveys, including five endemic gecko species and two endemic species of snakes (see Sumontha et al., 2017). The reasons behind such exceptional herpetofaunal endemism are yet unclear; it is remarkable that most reptiles that are endemic to Sai Yok District are associated with limestone habitats; this is also the case for Siamophryne troglodytes. Like the other representatives of Thai endemic herpetofauna that live in caves or their direct surroundings, the newly discovered genus has to cope with a high degree of human disturbance (Pauwels et al., 2016), in this case - due to illegal mining of bat guano that causes destruction and modification of the cave ecosystem. This may pose a serious threat for Siamophryne troglodytes in the future; immediate assessment of its conservation status on national and international levels, conservation measures at the type locality that will minimize the 
861 modification of the natural habitat by humans, as well as intensive surveys for the new 862 localities are essential for the protection of this relict frog lineage.

863 The discovery of Siamophryne troglodytes further demonstrates the key role of 864 limestone karst areas as arks of highly endangered biodiversity. Geological structure, 865 errosion and subterranean water drainages of limestone areas permanently provide unique 866 diversity of microrefugia with numerous shelters, like cracks and caves (Clements et al., 867 2006). These humid microhabitats might provide an efficient environmental buffer for 868 small vertebrates during periods of climate change (Glaw et al., 2006). Isolated limestone 869 massifs throughout the world are known as hotspots of vertebrate endemism and 870 persistence (Oliver et al., 2017a). Karst areas act as microrefugia for relict amphibian 871 species (see Sket, 1997; Min et al., 2005; Glaw et al., 2006; Milto et al., 2013). Karsts 872 are also known as important "biodiversity arks" for both surface and cave faunas 873 (Clements et al., 2006) with numerous new species of amphibians and reptiles being 874 discovered from limestone areas (e.g. see Köhler et al., 2010; Nazarov et al., 2014; 875 Rakotoarison et al., 2017; Grismer \& Grismer, 2017; Grismer et al., 2017 and references 876 therein). Ironically, though acting as major biodiversity hotspots, limestone karst areas 877 are critically endangered due to intensive deforestation and cement manufacturing; their 878 continued exploitation for limestone cannot be stopped (Clements et al., 2006). Our study 879 thus calls for further focused survey and conservation efforts on karst herpetofauna in 880 Southeast Asia. western Thailand, belongs to the subfamily Asterophryinae, which is most diverse in Australasia. Siamophryne and its sister genus Gastrophrynoides are the only two 886 asterophryine lineages found in the areas derived from the Eurasian landmass. Our work demonstrates that Siamophryne troglodytes represents an old lineage of the initial radiation of Asterophryinae which took place in the mainland Southeast Asia. Our results 889 strongly support the "out of Indo-Eurasia" biogeographic scenario for this group of frogs. 
890 To date, the new frog is the only known asterophryine with a free-living tadpole and 891 troglophilous life style. Further studies might reveal new members of Asterophryinae in 892 the mainland Southeast Asia.

893

894

895

896

897

898

899

900

901

902

903

904

905

906

907

908

909

910

911

912

913

914

915

916

917

\section{Acknowledgements}

We would like to thank the Laboratory Animal Research Center, University of Phayao and The Institute of Animal for Scientific Purposes Development (IAD) Thailand for the permission to work in the field and Niruth Chomngam, Chaowalit Songsangchote and Akrachai Aksornneam for help during the field work. We are most grateful to Yu Lee (Chinese Culture University, Taipei) for providing photos of Gastrophrynoides. NAP thanks Valentina D. Kretova (Biological Faculty, Lomonosov Moscow State University) for help with preparation of figures, Vladislav Gorin (Biological Faculty, Lomonosov Moscow State University) for help and assistance in the lab, Duong Van Tang (Biological Faculty, Lomonosov Moscow State University) for help with phylogenetic analyses and Alexandra A. Elbakyan for help with accessing required literature. We are indebted to Evgeniya N. Solovyeva (Zoological Museum of Moscow University) for help with primer design and to Egill Scallagrimsson and Natalia Ershova for proofreading. We express our sincere gratitude to Gabriela Parra Olea and the three anonymous reviewers for their useful suggestions on the earlier version of the manuscript.

\section{References}

Blackburn DC, Siler CD, Diesmos AC, McGuire JA, Cannatella DC, Brown RM. 2013. An adaptive radiation of frogs in a southeast asian island archipelago. Evolution 67(9):2631-2646.

Bossuyt F, Roelants K. 2009. Anura. Hedges SB, Kumar S eds. The Timetree of Life: 357-364. New York, USA, Oxford University Press.

Burton TC. 1986. A reassessment of the Papuan subfamily Asterophryinae (Anura: Microhylidae). Records of the South Australian Museum 19:405-450. 
918 Castresana J. 2000. Selection of conserved blocks from multiple alignments for their use

919

920

921

922

923

924

925

926

927

928

929

930

931

932

933

934

935

936

937

938

939

940

941

942

943

944

945

946

947

948

949

950

951

952

953

954 in phylogenetic analysis. Molecular Biology and Evolution 17:540-552. DOI: 10.1093/oxfordjournals.molbev.a026334

Chan KO, Grismer LL, Ahmad N, Belabut DM. 2009. A new species of Gastrophrynoides (Anura: Microhylidae): an addition to a previously monotypic genus and a new genus for Peninsular Malaysia. Zootaxa 2124:63-68.

Clements R, Sodhi NS, Schilthuizen M, Ng PKL. 2006. Limestone Karsts of Southeast Asia: Imperiled Arks of Biodiversity. BioScience 56(09):733-746.

De Sá RO, Streicher JW, Sekonyela R, Forlani MC, Loader SP, Greenbaum E, Richards SJ, Haddad CFB. 2012. Molecular phylogeny of microhylid frogs (Anura: Microhylidae) with emphasis on relationships among New World genera. $B M C$ Evolutionary Biology 12(241):1-21.

Deng X, Wang S, Liang X, Jiang J, Wang B, Deng L. 2015. The complete mitochondrial genome of Kaloula rugifera (Amphibia, Anura, Microhylidae). Mitochondrial DNA: 1-2.

Felsenstein J. 1985. Confidence limits on phylogenies: an approach using the bootstrap. Evolution 39(4): 783-791. DOI:10.2307/2408678

Feng YJ, Blackburn DC, Liang D, Hillis DM, Wake DB, Cannatella DC, Zhang P. 2017. Phylogenomics reveals rapid, simultaneous diversification of three major clades of Gondwanan frogs at the Cretaceous-Paleogene boundary. Proceedings of the National Academy of Sciences USA; 114(29):E5864-E5870. DOI:10.1073/pnas.1704632114. Epub 2017 Jul 3.

Glaw F, Vences M. 1997. Anuran eye colouration: definitions, variation, taxonomic implications and possible functions. In: W. Bohme, W. Bischoff \& T. Ziegler (Eds), Herpetologia Bonnensis, Bonn: 125-138.

Glaw F, Hoegg S, Vences M. 2006. Discovery of a new basal relict lineage of Madagascan frogs and its implications for mantellid evolution. Zootaxa 1334:2743.

Gosner KL. 1960. A simplified table for staging anuran embryos and larvae. Herpetologica 16:183-190.

Grismer LL, Grismer JL. 2017. A re-evaluation of the phylogenetic relationships of the Cyrtodactylus condorensis group (Squamata; Gekkonidae) and a suggested protocol for the characterization of rock-dwelling ecomorphology in Cyrtodactylus. Zootaxa 4300(4):486-504. DOI:10.11646/zootaxa.4300.4.2

Grismer LL, Wood PL Jr, Myint Kyaw Thura, Thaw Zin, QUah ESH, Murdoch ML, Grismer MS, Aung Lin, Htet Kyaw, Ngwe Lwin. 2017. Twelve new species of Cyrtodactylus Gray (Squamata: Gekkonidae) from isolated limestone habitats in 
955

956

957

958

959

960

961

962

963

964

965

966

967

968

969

970

971

972

973

974

975

976

977

978

979

980

981

982

983

984

985

986

987

988

989

990

991

eastcentral and southern Myanmar demonstrate high localized diversity and unprecedented microendemism. Zoological Journal of the Linnean Society 45(306-07):251-484. DOI:10.1111/j.1096-3642.1965.tb00500.x

Günther R, Richards SJ, Bickford DP, Johnston GR. 2012b. A new egg-guarding species of Oreophryne (Amphibia, Anura, Microhylidae) from southern Papua New Guinea. Zoosystematics and Evolution. Mitteilungen aus dem Museum für Naturkunde in Berlin 88:223-230.

Günther R, Richards SJ, Dahl CS. 2014. Nine new species of microhylid frogs from the Muller Range in western Papua New Guinea (Anura, Microhylidae). Vertebrate Zoology. Dresden 64:59-94.

Günther R, Richards SJ, Tjaturadi B. 2016. A new species of the frog genus Pseudocallulops from the Foja Mountains in northwestern New Guinea (Amphibia, Microhylidae). Russian Journal of Herpetology 23:63-69.

Günther R, Richards SJ. 2016. Description of a striking new Mantophryne species (Amphibia, Anura, Microhylidae) from Woodlark Island, Papua New Guinea. Zoosystematics and Evolution 92:111-118.

Günther R, Stelbrink B, von Rintelen T. 2010. Oninia senglaubi, another new genus and species of frog (Amphibia, Anura, Microhylidae) from New Guinea. Zoosystematics and Evolution. Mitteilungen aus dem Museum für Naturkunde in Berlin 86:245-256.

Günther R, Stelbrink B, von Rintelen T. 2012a. Three new species of Callulops (Anura: Microhylidae) from western New Guinea. Vertebrate Zoology. Dresden 62:407423.

Günther R. 2009. Metamagnusia and Pseudocallulops, two new genera of microhylid frogs from New Guinea (Amphibia, Anura, Microhylidae). Zoosystematics and Evolution. Mitteilungen aus dem Museum für Naturkunde in Berlin 85:171-187.

Günther R. 2017. A redescription, a revalidation, and a new description within the microhylid genus Austrochaperina (Anura: Microhylidae). Vertebrate Zoology. Dresden 67(2):207-222.

Hall TA. 1999. BioEdit: a user-friendly biological sequence alignment editor and analysis program for Windows 95/98/NT. In: Nucleic acids symposium series. [London]: Information Retrieval Ltd., c1979-c2000: 95-98.

Hedges SB. 1994. Molecular evidence for the origin of birds. Proceedings of the National Academy of Sciences 91(7):2621-2624. DOI:10.1073/pnas.91.7.2621

Hill ED. 2009. Salticidae of the Antarctic land bridge. Peckhamia 76.1:1-14.

Hillis DM, Moritz C, Mable BK, Graur D. 1996. Molecular systematics. Vol. 23, Sinauer Associates, Inc., Publishers, Sunderland, Massachusetts, USA. 
992 Hoskin CJ. 2004. Australian microhylid frogs (Cophixalus and Austrochaperina): 993 phylogeny, taxonomy, calls, distributions and breeding biology. Australian $994 \quad$ Journal of Zoology 52: 237-269.

995 Hou M, Wu Y-k, Yang K, Zheng S, Yuan Z-y, Li P. 2014. A missing geographic link in 996 the distribution of the genus Echinotriton (Caudata: Salamandridae) with 997 998 999

1000

1001

1002

1003

1004

1005

1006

1007

1008

1009

1010

1011

1012

1013

1014

1015

1016

1017

1018

1019

1020

1021

1022

1023

1024

1025

1026

1027

Huelsenbeck JP, Hillis DM. 1993. Success of phylogenetic methods in the four-taxon case. Systematic Biology 42(3):247-264. DOI:10.2307/2992463

Huelsenbeck JP, Ronquist F. 2001. MRBAYES: Bayesian inference of phylogenetic trees. Bioinformatics 17(8):754-755. DOI:10.1093/bioinformatics/17.8.754

Huxley TH. 1868. On the Classification and Distribution of the Alectoromorphae and Heteromorphae. Proceedings of the Zoological Society of London: 294-319.

Igawa T, Kurabayashi A, Usuki C, Fujii T, Sumida M. 2008. Complete mitochondrial genomes of three neobatrachian anurans: A case study of divergence time estimation using different data and calibration settings. Gene 407(1-2):116-129.

IUCN Standards and Petitions Subcommittee. 2016. Guidelines for Using the IUCN Red List Categories and Criteria. Version 12. Prepared by the Standards and Petitions Subcommittee. Downloadable from: http://www.iucnredlist.org/documents/RedListGuidelines.pdf (accessed on 12 March 2017).

Jobb G, von Haeseler A, Strimmer K. 2004. TREEFINDER: a powerful graphical analysis environment for molecular phylogenetics. BMC Evolutionary Biology 4:18.

Köhler F, Günther R. 2008. The radiation of microhylid frogs (Amphibia: Anura) on New Guinea: A mitochondrial phylogeny reveals parallel evolution of morphological and life history traits and disproves the current morphology-based classification. Molecular Phylogenetics and Evolution 47:353-365.

Köhler J, Vences M, D’Cruze N, Glaw F. 2010. Giant dwarfs: discovery of a radiation of large-bodied 'stump-toed frogs' from karstic cave environments of northern Madagascar. Journal of Zoology 282:21-38.

Kraus F, Allison A. 2003. A new species of Callulops (Anura: Microhylidae) from Papua New Guinea. Pacific Science. Honolulu 57:29-38.

Kraus F. 2010. New genus of diminutive microhylid frogs from Papua New Guinea. ZooKeys 48:39-59.

Kraus F. 2011. New frogs (Anura: Microhylidae) from the mountains of western Papua New Guinea. Records of the Australian Museum 63:53-60. 
1028 Kraus F. 2013a. Three new species of Oreophryne (Anura, Microhylidae) from Papua

1029

1030

1031

1032

1033

1034

1035

1036

1037

1038

1039

1040

1041

1042

1043

1044

1045

1046

1047

1048

1049

1050

1051

1052

1053

1054

1055

1056

1057

1058

1059

1060

1061

1062

1063

1064 New Guinea. ZooKeys 333:93-121.

Kraus F. 2013b. A new species of Hylophorbus (Anura: Microhylidae) from Papua New Guinea. Current Herpetology. Kyoto 32:102-111.

Kraus F. 2014. A new species of Liophryne (Anura: Microhylidae) from Papua New Guinea. Journal of Herpetology 48:255-261.

Kraus F. 2016. Ten new species of Oreophryne (Anura, Microhylidae) from Papua New Guinea. Zootaxa 4195:1-68.

Kraus F. 2017. A new species of Oreophryne (Anura: Microhylidae) from the mountains of southeastern Papua New Guinea. Current Herpetology. Kyoto 36:105-115.

Kurabayashi A, Matsui M, Belabut DM, Yong H-S, Ahmad N, Sudin A, Kuramoto M, Hamidy A, Sumida M. 2011. From Antarctica or Asia? New colonization scenario for Australian-New Guinean narrow mouth toads suggested from the findings on a mysterious genus Gastrophrynoides. BMC Evolutionary Biology 11(175):1-12.

Matsui M, Hamidy A, Belabut DM, Ahmad N, Panha S, Sudin A, Khonsue W, Oh H-S, Yong H-S, Jiang J-P. 2011. Systematic relationships of Oriental tiny frogs of the family Microhylidae (Amphibia, Anura) as revealed by mtDNA genealogy. Molecular Phylogenetics and Evolution 61(1);167-176. DOI:10.1016/j.ympev.2011.05.015

Matsui M, Shimada T, Liu W-Z, Maryati M, Khonsue W, Orlov N. 2006. Phylogenetic relationships of Oriental torrent frogs in the genus Amolops and its allies (Amphibia, Anura, Ranidae). Molecular Phylogenetics and Evolution 38(3):659666. DOI:10.1016/j.ympev.2005.11.019

Mayr E. 1944. Wallace's Line in the Light of Recent Zoogeographic Studies. The Quarterly Review of Biology 19(1):1-14. DOI:10.1086/394684

Menzies JI, Tyler MJ. 1977. The systematics and adaptations of some Papuan microhylid frogs which live underground. Journal of Zoology London 183:431-464.

Menzies JI. 2006. The Frogs of New Guinea and the Solomon Islands. Pensoft Publisher Sofia. 210.

Milto KD, Poyarkov NA, Orlov NL, Nguyen TT. 2013. Two new rhacophorid frogs from Cat Ba Island, Gulf of Tonkin (Hai Phong Province, Vietnam). Russian Journal of Herpetology 20(4):287-300.

Min MS, Yang SY, Bonett RM, Vieites DR, Brandon RA, Wake DB. 2005. Discovery of the first Asian plethodontid salamander. Nature 435:87-90.

Nazarov RA, Poyarkov NA, Orlov NL, Nguyen NS, Milto KD, Martynov AA, Konstantinov EL, Chulisov AS. 2014. A review of Cyrtodactylus (Reptilia: 
1065

1066

1067

1068

1069

1070

1071

1072

1073

1074

1075

1076

1077

1078

1079

1080

1081

1082

1083

1084

1085

1086

1087

1088

1089

1090

1091

1092

1093

1094

1095

1096

1097

1098

1099

1100

Sauria: Geckonidae) fauna of Laos with description of four new species. Proceedings of the Zoological Institute RAS 318(4):391-423.

Nguyen TL, Poyarkov NA Jr., Nguyen TT, Nguyen TA, Nguyen VH, Gorin VA, Murphy RW, Nguyen SN. 2018. A new species of the genus Microhyla Tschudi, 1838 (Amphibia: Anura: Microhylidae) from Tay Nguyen Plateau, Central Vietnam. Zootaxa, in press.

Oliver LA, Rittmeyer EN, Kraus F, Richards SJ, Austin CC. 2013. Phylogeny and phylogeography of Mantophryne (Anura: Microhylidae) reveals cryptic diversity in New Guinea. Molecular Phylogenetics and Evolution 67:600-607.

Oliver PM, Laver RJ, De Mello Martins F, Pratt RC, Hunjan S, Moritz CC. 2017a. A novel hotspot of vertebrate endemism and an evolutionary refugium in tropical Australia. Diversity and Distributions 23:53-66.

Oliver PM, Iannella A, Richards SJ, Lee MSY. 2017b. Mountain colonisation, miniaturisation and ecological evolution in a radiation of direct-developing New Guinea Frogs (Choerophryne, Microhylidae). PeerJ 5:e3077. DOI:10.7717/peerj.3077

Palumbi S, Martin A, Romano S, McMillan W, Stice L, Grabowski G. 1991. The Simple Fool's Guide to PCR, Version 2.0, privately published document compiled by S. Palumbi. Dept. Department of Zoology, University of Hawaii, Honolulu, 96822.

Parker HW. 1934. Monograph of the frogs of the family Microhylidae. Trustees of the British Museum, London 212. DOI:10.2307/1436128

Pauwels OSG, Sumontha M, Ellis M. 2016. Les geckos cavernicoles des grottes aménagées et exploitées de Thaïlande: diversité et problématiques de conservation. In: Abstracts. 44e congrès de la Société Herpétologique de France, 2e congrès franco-belge d'Herpétologie. Société Herpétologique de France \& Natagora: 36.

Peloso PL, Frost DR, Richards SJ, Rodrigues MT, Donnellan S, Matsui M, Raxworthy CJ, Biju S, Lemmon EM, Lemmon AR. 2016. The impact of anchored phylogenomics and taxon sampling on phylogenetic inference in narrow-mouthed frogs (Anura, Microhylidae). Cladistics 32(2):113-140. DOI:10.1111/cla.12118

Posada D, Crandall KA. 1998. Modeltest: testing the model of DNA substitution. Bioinformatics 14(9):817-818. DOI:10.1093/bioinformatics/14.9.817

Poyarkov JNA, Vassilieva AB, Orlov NL, Galoyan EA, Tran D, Le DTT, Kretova VD, Geissler P. 2014. Taxonomy and distribution of narrow-mouth frogs of the genus Microhyla Tschudi, 1838 (Anura: Microhylidae) from Vietnam with descriptions of five new species. Russian Journal of Herpetology 21(2):89-148. 
1101 Poyarkov NA Jr., Duong TV, Orlov NL, Gogoleva SS, Vassilieva AB, Nguyen LT,

1102

1103

1104

1105

1106

1107

1108

1109

1110

1111

1112

1113

1114

1115

1116

1117

1118

1119

1120

1121

1122

1123

1124

1125

1126

1127

1128

1129

1130

1131

1132

1133

1134

1135 Nguyen VHD, Nguyen SN, Che J, Mahony S. 2017. Molecular, morphological and acoustic assessment of the genus Ophryophryne (Anura, Megophryidae) from Langbian Plateau, southern Vietnam, with description of a new species. ZooKeys 672:49-120. DOI:10.3897/zookeys.672.10624

Poyarkov NA Jr., Orlov NL, Moiseeva AV, Pawangkhanant P, Ruangsuwan T, Vassilieva AB, Galoyan EA, Nguyen TT, Gogoleva SS. 2015. Sorting out moss frogs: mtDNA data on taxonomic diversity and phylogenetic relationships of the Indochinese species of the genus Theloderma (Anura, Rhacophoridae). Russian Journal of Herpetology 22(4):241-280.

Pyron RA, Wiens JJ. 2011. A large-scale phylogeny of Amphibia including over 2800 species, and a revised classification of advanced frogs, salamanders, and caecilians. Molecular Phylogenetics and Evolution 61:543-583.

Rakotoarison A, Scherz MD, Glaw F, Köhler J, Andreone F, Franzen M, Glos J, Hawlitschek O, Jono T, Mori A, Ndriantsoa SH, Raminosoa NR, Riemann JC, Rödel MO, Rosa GM, Vieites DR, Crottini A, Vences M. 2017. Describing the smaller majority: integrative taxonomy reveals twenty-six new species of tiny microhylid frogs (genus Stumpffia) from Madagascar. Vertebrate Zoology 67(3):271-398.

Richards SJ, Iskandar DT. 2000. A new minute Oreophryne (Anura: Microhylidae) from the mountains of Irian Jaya, Indonesia. Raffles Bulletin of Zoology. Singapore 48:257-262.

Richards SJ, Johnston GR, Burton TC. 1992. A new species of microhylid frogs (genus Cophixalus) from the Star Mountains, central New Guinea. Science in New Guinea. Port Moresby 18:141-145.

Richards SJ, Johnston GR, Burton TC. 1994. A remarkable new asterophryine microhylid frog from the mountains of New Guinea. Memoirs of the Queensland Museum 37:281-286.

Rittmeyer EN, Allison A, Gründler MC, Thompson DK, Austin CC. 2012. Ecological guild evolution and the discovery of the world's smallest vertebrate. PLoS One 7(1: e29797):1-6.

Rivera JA, Kraus F, Allison A, Butler MA. 2017. Molecular phylogenetics and dating of the problematic New Guinea microhylid frogs (Amphibia: Anura) reveals elevated speciation rates and need for taxonomic reclassification. Molecular Phylogenetics and Evolution 112:1-11. 
1136 Ronquist F, Huelsenbeck JP. 2003. MrBayes 3: Bayesian phylogenetic inference under

1137

1138

1139

1140

1141

1142

1143

1144

1145

1146

1147

1148

1149

1150

1151

1152

1153

1154

1155

1156

1157

1158

1159

1160

1161

1162

1163

1164

1165

1166

1167

1168

1169

1170

1171

1172
19(12):1572-1574.

models. Bioinformatics

DOI:10.1093/bioinformatics/btg180

Sambrook J, David W. 2001. Molecular cloning: a laboratory manual, 3rd edn.. Plainview. Cold Spring Harbor Laboratory Press, New York.

Sano N, Kurabayashi A, Fujii T, Yonekawa H, Sumida M. 2005. Complete nucleotide sequence of the mitochondrial genome of Schlegel's tree frog Rhacophorus schlegelii (family Rhacophoridae): duplicated control regions and gene rearrangements. Genes \& Genetic Systems. 80(3):213-224.

Savage JM. 1973. The geographic distribution of frogs: pattern and predictions. In: Evolutionary Biology of Anurans: Contemporary Research on Major Problems. Edited by: Vial JL. Colombia, Missouri: University of Missouri Press; 351-445.

Savage JM. 1975. Systematics and distribution of the Mexican and Central American stream frogs related to Eleutherodactylus rugulosus. Copeia 1975(2):254-306. DOI:10.2307/1442883

Scherz MD, Glaw F, Vences M, Andreone F, Crottini A. 2016. Two new species of terrestrial microhylid frogs (Microhylidae: Cophylinae: Rhombophryne) from northeastern Madagascar. Salamandra 52:91-106.

Sket B. 1997. Distribution of Proteus (Amphibia: Urodela: Proteidae) and its possible explanation. Journal of Biogeography 24:263-280.

Sumontha M, Kunya K, Dangsri S, Pauwels OSG. 2017. Oligodon saiyok, a new limestone-dwelling kukri snake (Serpentes: Colubridae) from Kanchanaburi Province, western Thailand. Zootaxa 4294(3):316-328.

Tamura K, Stecher G, Peterson D, Filipski A, Kumar S. 2013. MEGA6: molecular evolutionary genetics analysis version 6.0. Molecular Biology and Evolution 30(12):2725-2729. DOI:10.1093/molbev/mst197

Thompson JD, Gibson TJ, Plewniak F, Jeanmougin F, Higgins DG. 1997. The CLUSTAL_X windows interface: flexible strategies for multiple sequence alignment aided by quality analysis tools. Nucleic acids research 25(24):48764882. DOI:10.1093/nar/25.24.4876

Trueb L. 1968. Cranial osteology of the hylid frog, Smilisca baudini. University of Kansas Publications, Museum of Natural History 18:11-35.

Trueb L. 1973. Bones, frogs, and evolution. In: Vial, J. L. (ed.) Evolutionary biology of the anurans: Contemporary research on major problems. - University of Missouri Press, USA: 65-132.

Van Bocxlaer I, Roelants K, Biju SD, Nagaraju J, Bossuyt F. 2006. Late Cretaceous vicariance in Gondwanan amphibians. PLoS One 1:e74. 
1173 Van der Meijden A, Vences M, Hoegg S, Boistel R, Channing A, Meyer A. 2007.

1174

1175

1176

1177

1178

1179

1180

1181

1182

1183

1184

1185

1186

1187

1188

1189

1190

1191

1192

1193

1194

1195

1196

1197

1198

1199

1200

1201

1202

1203

1204

1205

1206

1207

Nuclear gene phylogeny of narrow-mouthed toads (Family: Microhylidae) and a discussion of competing hypotheses concerning their biogeographical origins. Molecular Phylogenetics and Evolution 44:1017-1030.

Vassilieva AB, Galoyan EA, Gogoleva SS, Poyarkov NA Jr. 2014. Two new species of Kalophrynus Tschudi, 1838 (Anura: Microhylidae) from the Annamite mountains in southern Vietnam. Zootaxa 3796(3):401-434. DOI:10.11646/zootaxa.3796.3.1

Vassilieva AB, Trounov VL, Poyarkov NA Jr., Galoyan EA. 2017. The phytotelm tadpoles of Microhyla arboricola (Anura: Microhylidae) from Vietnam, with comments on reproductive biology and development. Zootaxa 4247(4):413-428. DOI:10.11646/zootaxa.4247.4.4

Vences M, Thomas M, Bonett RM, Vieites DR. 2005a. Deciphering amphibian diversity through DNA barcoding: chances and challenges. Philosophical Transactions of the Royal Society of London B: Biological Sciences 360(1462):1859-1868. DOI:10.1098/rstb.2005.1717

Vences M, Thomas M, van der Meijden, A, Chiari Y, Vieites DR. 2005b. Comparative performance of the 16S rRNA gene in DNA barcoding of amphibians. Frontiers in zoology 2(1):5.

Vieites DR, Wollenberg KC, Andreone F, Köhler J, Glaw F, Vences M. 2009. Vast underestimation of Madagascar's biodiversity evidenced by an integrative amphibian inventory. Proceedings of the National Academy of Sciences 106(20):8267-8272. DOI:10.1073/pnas.0810821106

Wilkinson JA, Drewes RC, Tatum OL. 2002. A molecular phylogenetic analysis of the family Rhacophoridae with an emphasis on the Asian and African genera. Molecular Phylogenetics and Evolution 24(2):265-273. DOI:10.1016/s10557903(02)00212-9

Wu X, Li Y, Zhang H, Yan L, Wu XB. 2014. The complete mitochondrial genome of Microhyla pulchra (Amphidia, Anura, Microhylidae). Mitochondrial DNA: 154155. DOI:10.1080/23802359.2016.1144107.

Yan F, Jiang K, Wang K, Jin J-Q, Suwannapoom C, Li C, Vindum JV, Brown RM, Che J. 2016. The Australasian frog family Ceratobatrachidae in China, Myanmar and Thailand: discovery of a new Himalayan forest frog clade. Zoological Research 37(1):7-14.

Zhang P, Zhou H, Chen YQ, Liu YF, Qu LH. 2005. Mitogenomic perspectives on the origin and phylogeny of living amphibians. Systematic Biology 54(3):391-400. 
1208 Zweifel RG, Menzies JI, Price D. 2003. Systematics of microhylid frogs, genus 1209 Oreophryne, from the North Coast Region of New Guinea. American Museum $1210 \quad$ Novitates 3415:1-31.

1211 Zweifel RG. 1972. Results of the Archbold Expeditions. No. 97. A revision of the frogs 1212 of the subfamily Asterophryinae, Family Microhylidae. Bulletin of the American $1213 \quad$ Museum of Natural History 148:411-546.

1214 Zweifel RG. 2000. Partition of the Australopapuan microhylid frog genus Sphenophryne 1215 1216 with descriptions of new species. Bulletin of the American Museum of Natural History 253:1-130. 


\section{Figure 1}

Known distribution of main Asterophryinae lineages and the type locality (green star) of Siamophryne troglodytes Gen. et sp. nov. in Kanchanaburi Province, Thailand.

Biogeographic borders: A -the Isthmus of Kra line, the approximate biogeographic border between Sundaland and Indochina; B-1 - the Wallace line (after Huxley, 1868); B-2 - the Wallace line (after Mayr, 1944); C - the Weber line; D - the Lyddeker line. The majority of the Asterophryinae genera inhabit Australasia east of the Wallace line (red) and the island of Bali; Gastrophrynoides is confined to Sundaland (Borneo and peninsular Malaysia);

Siamophryne troglodytes Gen. et sp. nov. is known from Indochina.

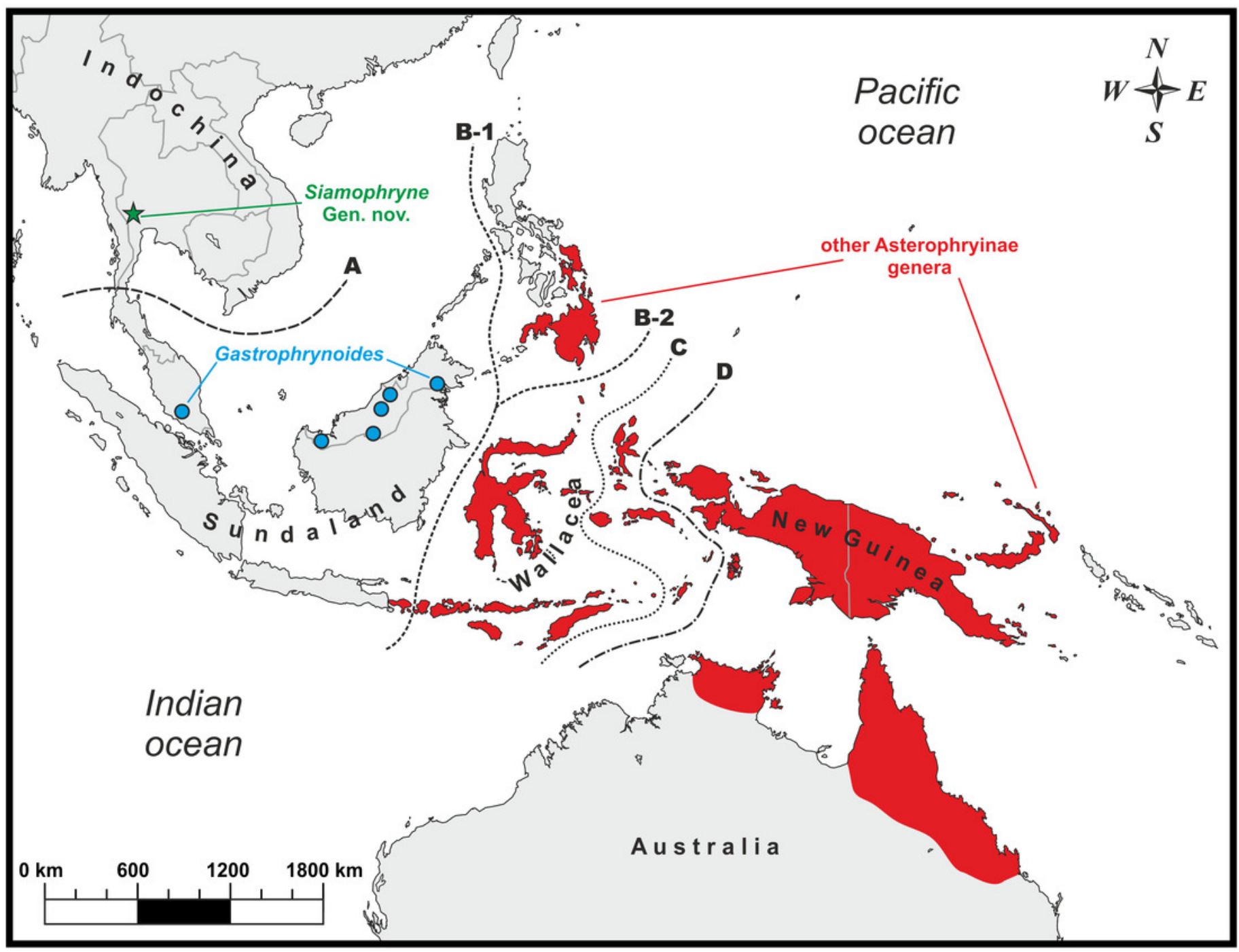




\section{Figure 2}

Bayesian inference dendrogram of Asterophryinae derived from the analysis of $2591 \mathrm{bp}$ of the 125 rRNA - 16S rRNA mtDNA gene fragment.

Voucher specimen IDs and Genbank access numbers are given in Table 2. Sequence of Rhacophorus schlegelii is used as an outgroup. Numbers near the branches represent posterior probability (PP) or bootstrap support values (BS, 1000 replicates) for the $\mathrm{BI} / \mathrm{ML}$ inferences respectively. " $A$ " denotes the subfamily Asterophryinae sensu lato node. Thumbnails show adult specimens of Siamophryne troglodytes Gen. et sp. nov. and Gastrophrynoides sp. (Malaysia); photos by N. A. Poyarkov and Yu Lee.

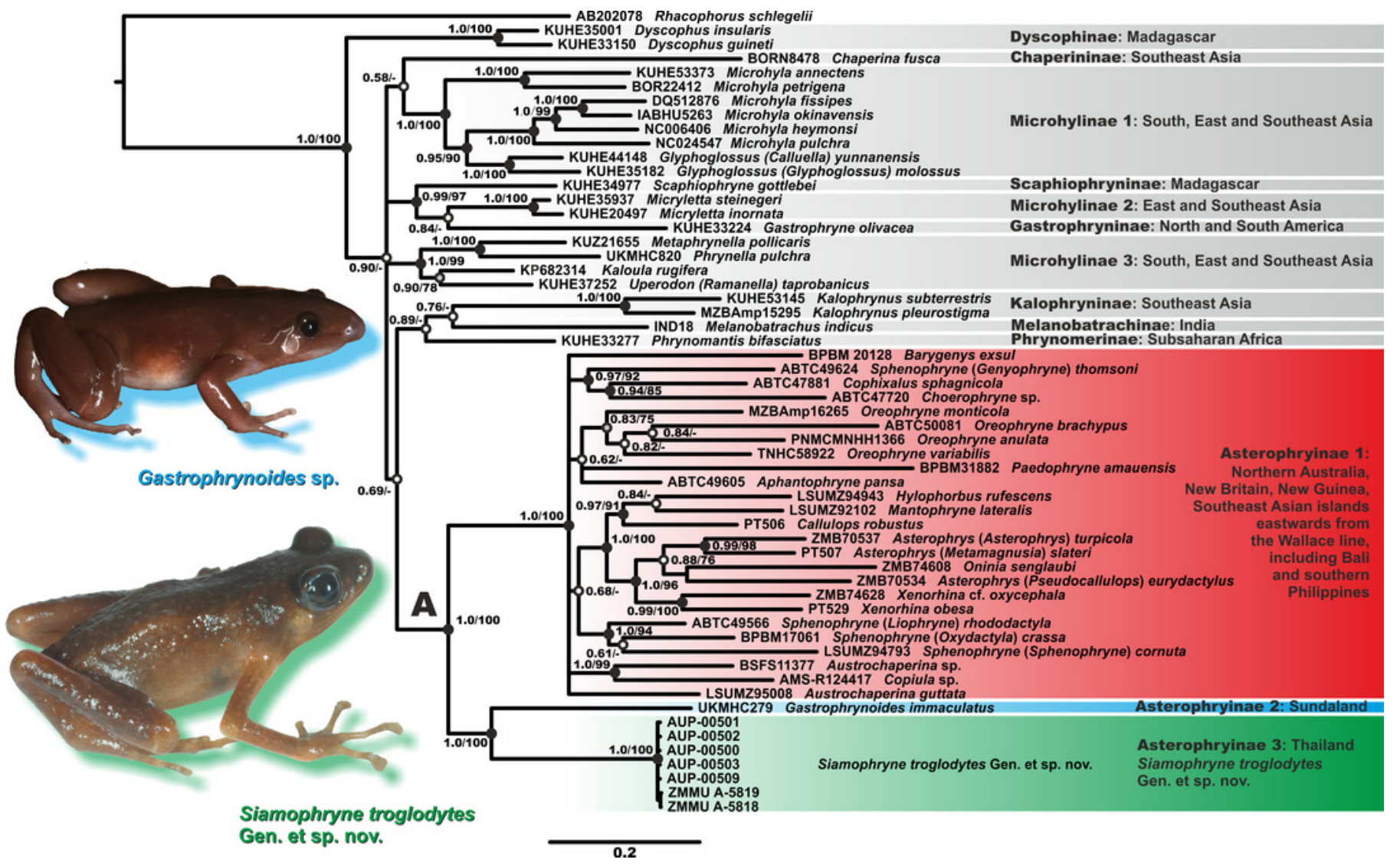




\section{Figure 3}

The male holotype of Siamophryne troglodytes Gen. et sp. nov. (AUP-00500) in preservative.

(A) Dorsal view; (B) ventral view; (C) lateral view of the head; (D) volar view of the right hand; (E) plantar view of the right foot. Photos by N. A. Poyarkov.

*Note: Auto Gamma Correction was used for the image. This only affects the reviewing manuscript. See original source image if needed for review. 

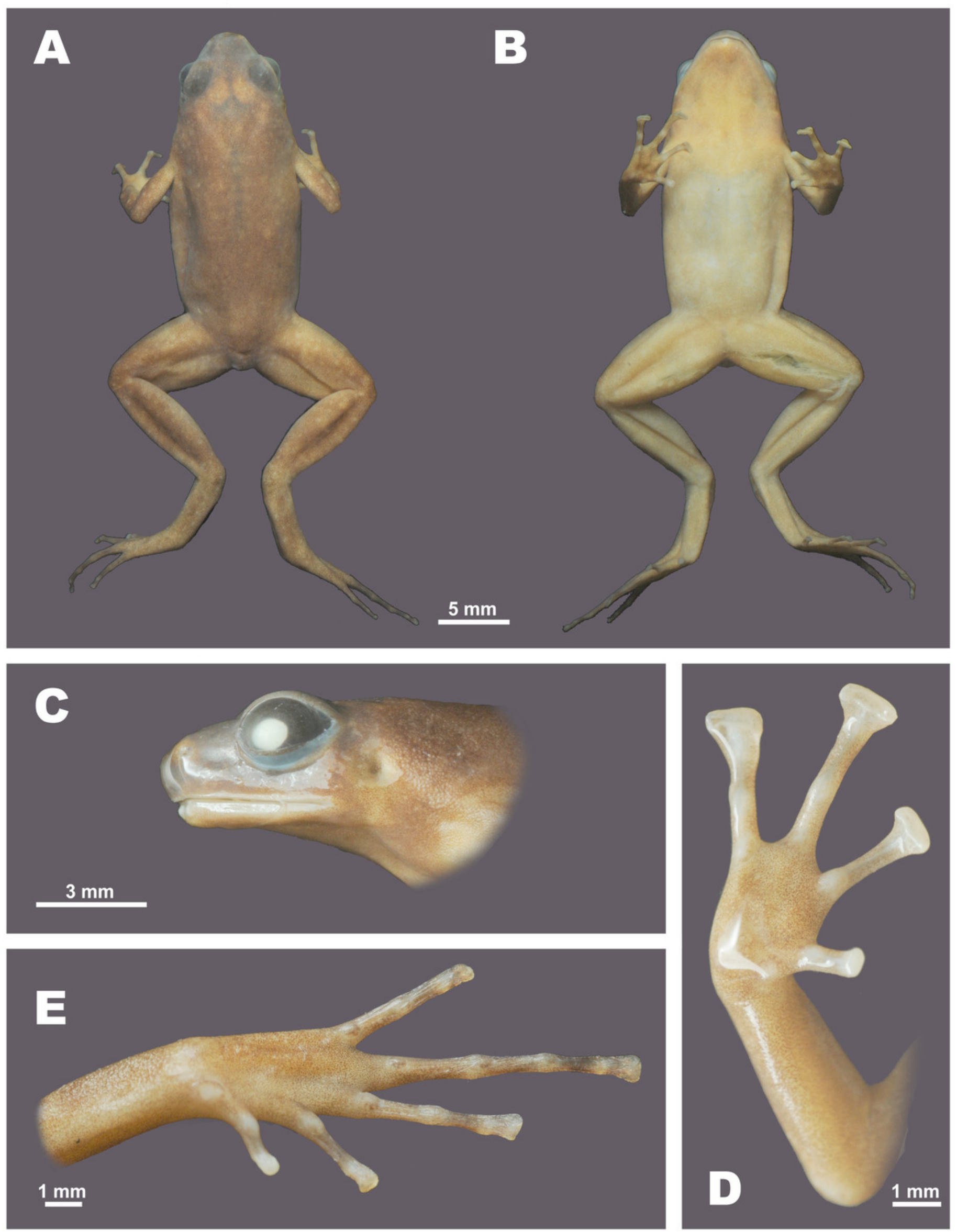
Figure 4

Morphological details of the male holotype of Siamophryne troglodytes Gen. et sp. nov. (AUP-00500) in preservative.

(A) Head in the lateral view; (B) volar view of the right hand; (C) plantar view of the right foot. Scale bar equals $2 \mathrm{~mm}$. Drawings by Valentina D. Kretova.

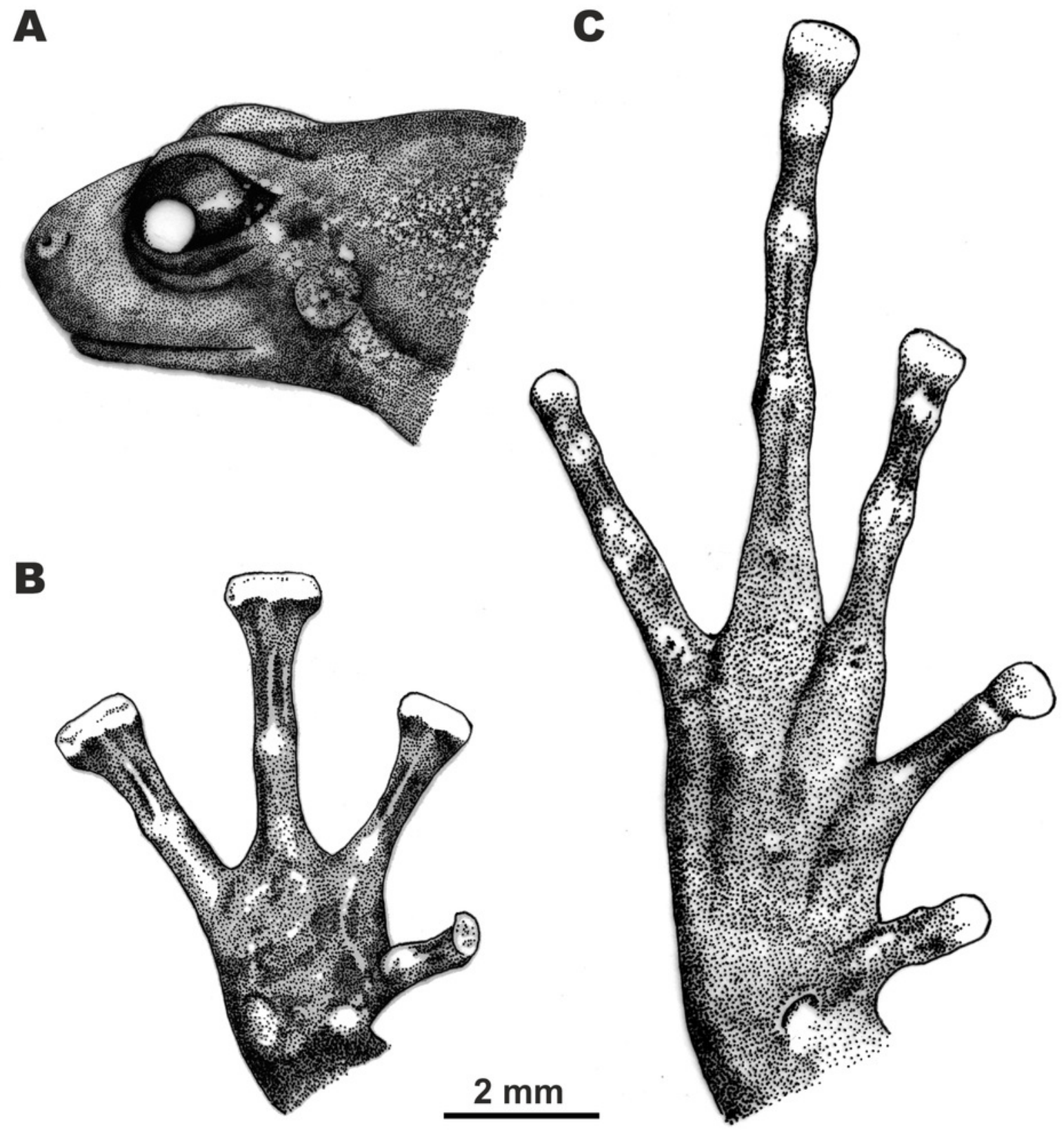




\section{Figure 5}

Male paratype of Siamophryne troglodytes Gen. et sp. nov. (ZMMU A-5818) in life in dorsolateral aspect.

Photo by N. A. Poyarkov.

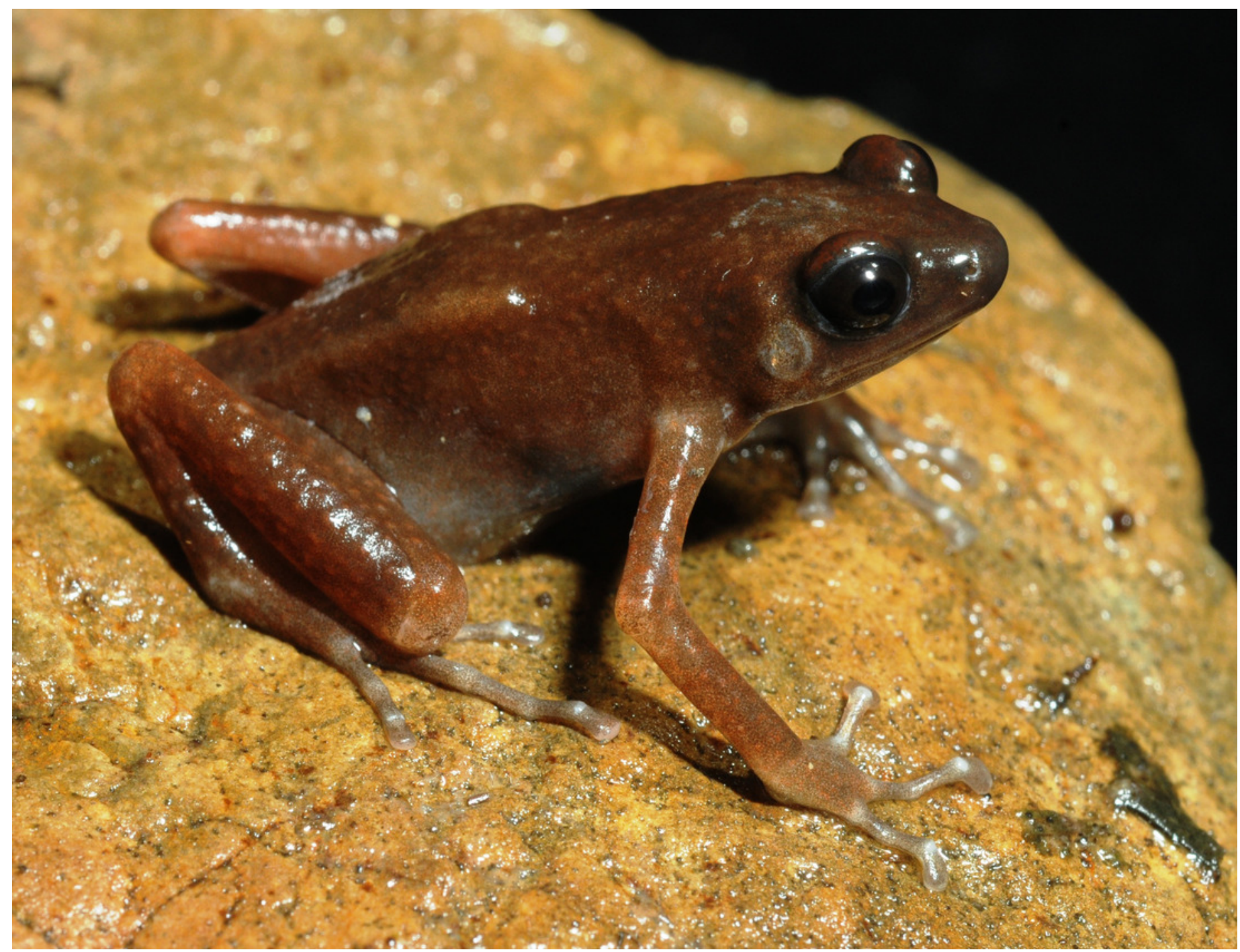




\section{Figure 6}

Osteology of Siamophryne troglodytes Gen. et sp. nov. (paratype, ZMMU A-5818).

The full skeleton is shown in (A) dorsal, and (B) ventral views; the right forelimb in (C) dorsal, and (D) volar aspects; and the right foot in (E) plantar, and (F) dorsal aspects. Digits numbered I-V. Abbreviations as follows: antbr. - os antebrachii (radius + ulna); carp.d.II-IV carpale distale F2-F4; centr. - centrale; clav. - clavicle; cor. - coracoid bone; crur. - os cruris (tibia + fibula); fem. - femoral bone; fib. - fibulare; hm. - humeral bone; il. - ilium; mtc.l-IV metacarpalia F1-F4; mtt.I-V - metatarsalia T1-T5; ph.d.IIV - finger phalanges F1-F4; ph.d.I-V toe phalanges T1-T5; pr.p.-m. - processus postero-medialis; prhl. - prehallux; prsac.v. presacral vertebrae; rad. - radiale; sac.v. - sacral vertebra; sc. - scapula; strn. - sternum; tar.d.II-III - tarsale distale T2-T3; tib. - tibiale; uln. - ulnare; ur. - urostyle. 


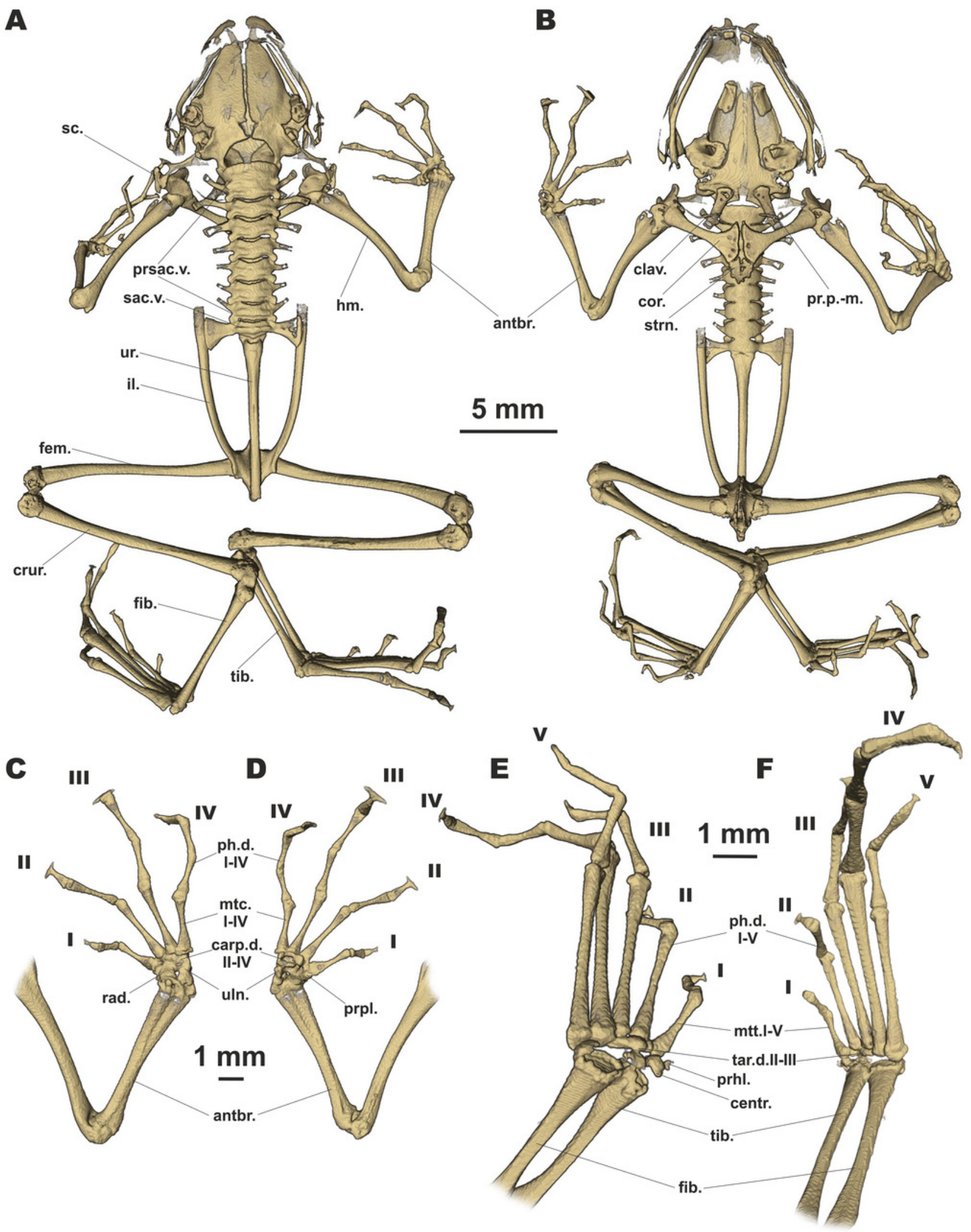




\section{Figure 7}

Head skeleton of Siamophryne troglodytes Gen. et sp. nov. (male paratype, ZMMU A5818).

The skull is shown in (A) dorsal, (B) ventral, (C) lateral, and (D) frontal views. Scale bar equals to $1 \mathrm{~mm}$. Abbreviations as follows: angspl. - angulosplenial; col. - columella; cond.oc. occipital condylus; dent. - dentary bone; exoc. - exoccipital; fpar. - frontoparietal bone; max. - maxilla; mmk. - mentomeckelian bone; nas. - nasal bone; pmax. - premaxilla; proot. prootic; psph. - parasphenoid; pter. - pterygoid; qj. - quadratojugal; smax. - septomaxilla; spheth. - sphenethmoid; sq. - squamosal; vom. - vomer.
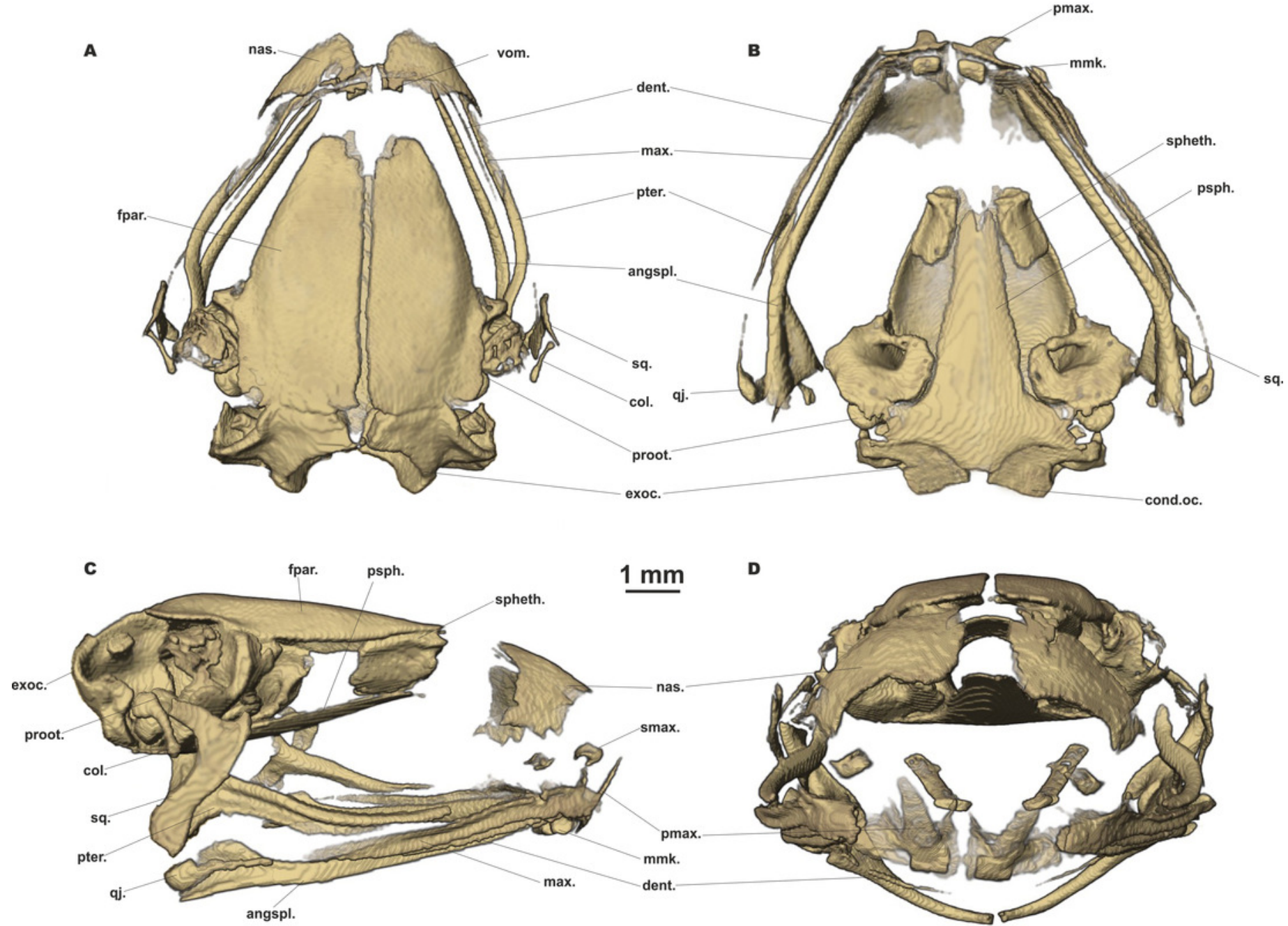


\section{Figure 8}

Tadpole of Siamophryne troglodytes Gen. et sp. nov. in life (AUP-00509; Gosner stage 36).

(A) In dorsal and (B) in ventral aspects. Scale bar equals to $5 \mathrm{~mm}$. Photos by N. A. Poyarkov.

\section{A}

\section{B}

$5 \mathrm{~mm}$ 


\section{Figure 9}

Tadpole of Siamophryne troglodytes Gen. et sp. nov. in preservative (AUP-00509; Gosner stage 36).

(A) In lateral, (B) in dorsal, and (C) in ventral views. Scale bar equals to $5 \mathrm{~mm}$. Photos by T. Ruangsuwan.

*Note: Auto Gamma Correction was used for the image. This only affects the reviewing manuscript. See original source image if needed for review.

$\mathbf{A}$

$\mathbf{B}$

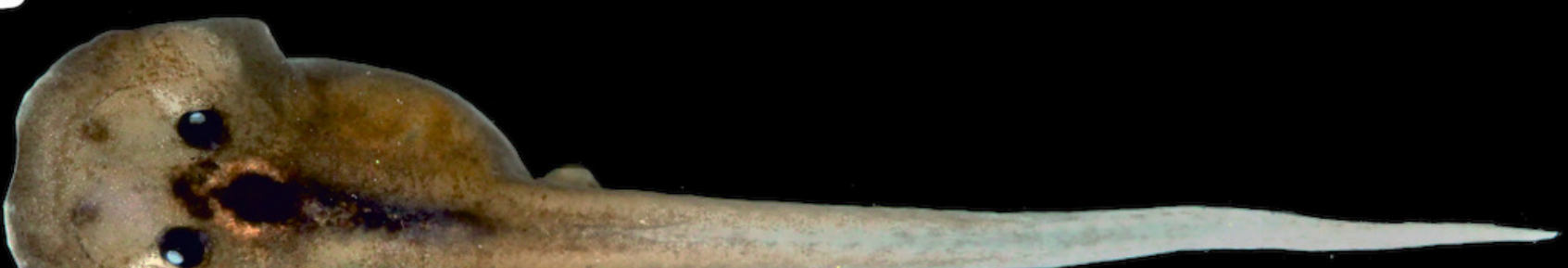

0

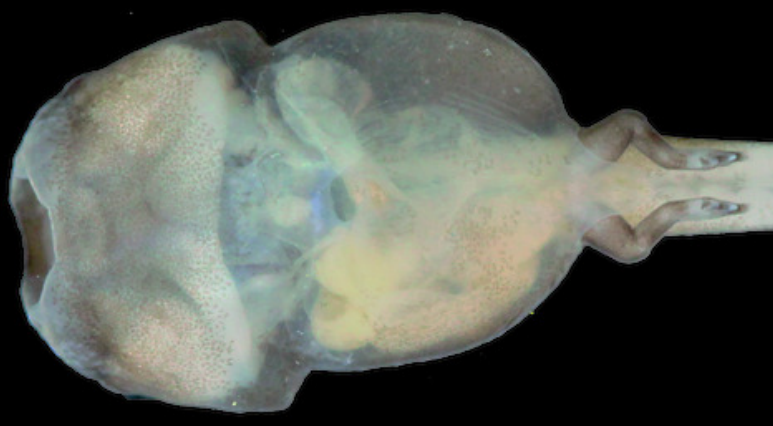




\section{Figure 10}

Breeding habitat of Siamophryne troglodytes Gen. et sp. nov. at the type locality - Sai Yok District, Kanchanaburi Province, northern Tenasserim Region, western Thailand.

(A) Entrance to the limestone cave where the frogs were recorded; (B) female in situ sitting on the limestone wall of the cave; (C) male in situ sitting in a water-filled crevice; (D) female in situ on the wall of the cave (photos by M. Sumontha); (E, F) tadpole in situ in a water-filled crevice (photos by T. Ruangsuwan). 

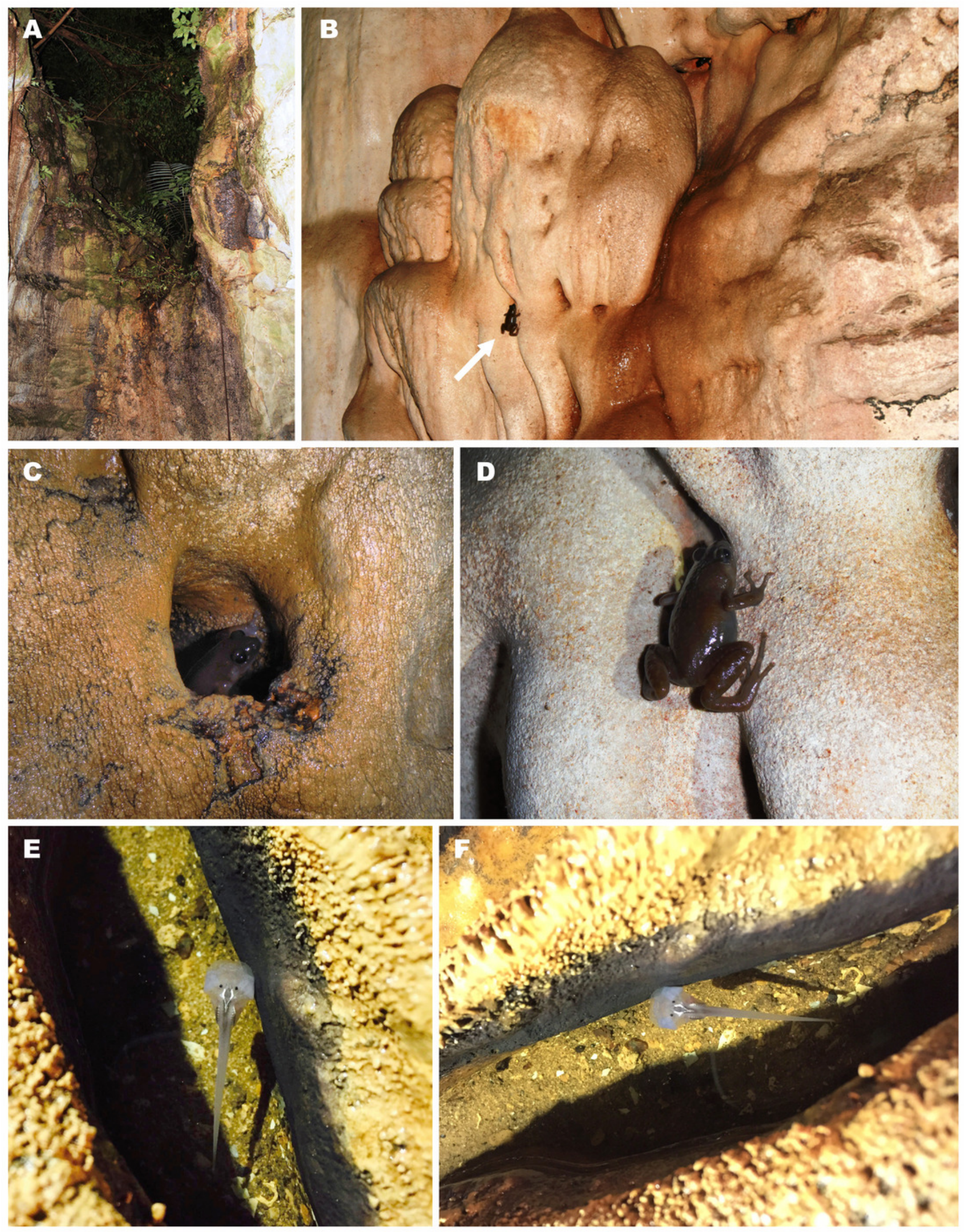
Table $\mathbf{1}$ (on next page)

Primers used in this study. 
1

\begin{tabular}{lll}
\hline \multicolumn{1}{c}{ Primer name } & \multicolumn{1}{c}{ Primer sequence } & \multicolumn{1}{c}{ Reference } \\
\hline Micro-1F-12stail & 12S rRNA & Nguyen et al., in press \\
Micro-600R-12stail & TAGAGGAGCCTGTTCTATAATCGATTC & Nguyen et al., in press \\
Micro-500F-12stail & CCACTTGAACCCACGACAGCTAGRAMACAA & Nguyen et al., in press \\
Micro-1200R-12stail & AGTAAAGGCGATYAAAAAATRTTTCAAAG & Nguyen et al., in press \\
12sA-L & AACTGGGATTAGATACCCCACTAT & Palumbi et al., 1991 \\
R-1169 & GTGGCTGCTTTTAGGCCCACT & Wilkinson et al., 2002 \\
\hline & 16S rRNA & \\
L-2188 & AAAGTGGGCCTAAAAGCAGCCA & Matsui et al., 2006 \\
$16 \mathrm{H}-1$ & CTCCGGTCTGAACTCAGATCACGTAGG & Hedges, 1994
\end{tabular}

2 
Table 2 (on next page)

Specimens and sequences of Siamophryne troglodytes Gen. et sp. nov. and outgroup representatives of Microhylidae and Rhacophoridae used in molecular analyses.

AN - GenBank accession numbers. 
1

\begin{tabular}{|c|c|c|c|c|}
\hline Group & GenBank AN & Species & Specimen ID & Reference \\
\hline Asterophryinae & DQ283195 & Aphantophryne pansa & ABTC 49605 & Frost et al., 2006 \\
\hline Asterophryinae & FR832625; FR832642 & Asterophrys turpicola & ZMB 70537 & Günther et al., 2010 \\
\hline Asterophryinae & JN048979; JN049004 & Austrochaperina guttata & LSUMZ 95008 & Rittmeyer et al., 2012 \\
\hline Asterophryinae & KC822485 & Austrochaperina sp. & BSFS 11377 & Blackburn et al., 2013 \\
\hline Asterophryinae & EU100119; EU100235 & Barygenys exsul & ВРВМ 20128 & Köhler \& Günther, 2008 \\
\hline Asterophryinae & KM509105 & Callulops robustus & PT-506 & Peloso et al., 2015 \\
\hline Asterophryinae & DQ283207 & Choerophryne sp. & ABTC 47720 & Frost et al., 2006 \\
\hline Asterophryinae & DQ283206 & Cophixalus sphagnicola & ABTC 47881 & Frost et al., 2006 \\
\hline Asterophryinae & DQ283208 & Copiula sp. & AMS R124417 & Frost et al., 2006 \\
\hline Asterophryinae & AB634647; AB634705 & Gastrophrynoides immaculatus & UKMHC 279 & Matsui et al., 2011 \\
\hline Asterophryinae & DQ283209 & Genyophryne thomsoni & ABTC 49624 & Frost et al., 2006 \\
\hline Asterophryinae & JX119248; JX119392 & Hylophorbus rufescens & LSUMZ 94943 & Oliver et al., 2013 \\
\hline Asterophryinae & DQ283199 & Liophryne rhododactyla & ABTC 49566 & Frost et al., 2006 \\
\hline Asterophryinae & JN048989; JN049014 & Mantophryne lateralis & LSUMZ 92102 & Rittmeyer et al., 2012 \\
\hline Asterophryinae & KM509160 & $\begin{array}{l}\text { Metamagnusia slateri } \\
\text { Siamophryne troglodytes Gen. }\end{array}$ & PT-507 & Peloso et al., 2015 \\
\hline Asterophryinae & MG682555 & & AUP-00500 & this work \\
\hline Asterophryinae & MG682556 & $\begin{array}{l}\text { et sp. nov. } \\
\text { Siamophryne troglodytes Gen. }\end{array}$ & AUP-00501 & this work \\
\hline Asterophryinae & MG682557 & $\begin{array}{l}\text { et sp. nov. } \\
\text { Siamophryne troglodytes Gen. }\end{array}$ & AUP-00502 & this work \\
\hline Asterophryinae & MG682558 & $\begin{array}{l}\text { et sp. nov. } \\
\text { Siamophryne troglodytes Gen. }\end{array}$ & AUP-00503 & this work \\
\hline Asterophryinae & MG682559 & $\begin{array}{l}\text { et sp. nov. (tadpole) } \\
\text { Siamophryne troglodytes Gen. }\end{array}$ & AUP-00509 & this work \\
\hline Asterophryinae & MG682553 & & ZMMU A-5818 & this work \\
\hline Asterophryinae & MG682554 & et sp. nov. & ZMMU A-5819 & this work \\
\hline Asterophryinae & FR832634; FR832635 & Oninia senglaubi & ZMB 74608 & Günther et al., 2010 \\
\hline Asterophryinae & KC822488 & Oreophryne anulata & PNMCMNHH 1366 & Blackburn et al., 2013 \\
\hline Asterophryinae & DQ283194 & Oreophryne brachypus & ABTC 50081 & Frost et al., 2006 \\
\hline Asterophryinae & AB634651; AB634709 & Oreophryne monticola & MZBAmp 16265 & Matsui et al., 2011 \\
\hline Asterophryinae & KC822489 & Oreophryne variabilis & TNHC 58922 & Blackburn et al., 2013 \\
\hline Asterophryinae & EU100323; EU100207 & Oxydactyla crassa & ВРВM 17061 & Köhler \& Günther, 2008 \\
\hline Asterophryinae & JN048996; JN049021 & Paedophryne amauensis & ВРВМ 31882 & Rittmeyer et al., 2012 \\
\hline Asterophryinae & FR832653; FR832636 & Pseudocallulops eurydactylus & ZMB 70534 & Günther et al., 2010 \\
\hline Asterophryinae & JX119386; JX119242 & Sphenophryne cornuta & LSUMZ 94793 & Oliver et al., 2013 \\
\hline Asterophryinae & FR832655; FR832638 & Xenorhina cf. oxycephala & ZMB 74628 & Günther et al., 2010 \\
\hline Asterophryinae & KM509212 & Xenorhina obesa & PT-529 & Peloso et al., 2015 \\
\hline Chaperininae & AB598318; AB598342 & Chaperina fusca & BORN 8478 & Matsui et al., 2011 \\
\hline Dyscophinae & AB634648; AB634706 & Dyscophus guineti & KUHE 33150 & Matsui et al., 2011 \\
\hline Dyscophinae & AB634649; AB634707 & Dyscophus insularis & KUHE 35001 & Matsui et al., 2011 \\
\hline
\end{tabular}




\begin{tabular}{lll} 
Gastrophryninae & AB634650; AB634708 & Gastrophryne olivacea \\
Kalophryninae & AB634642; AB634700 & Kalophrynus pleurostigma \\
Kalophryninae & AB634645; AB634703 & Kalophrynus subterrestris \\
Melanobatrachinae & KM509159 & Melanobatrachus indicus \\
Microhylinae & AB201182; AB201193 & Glyphoglossus molossus \\
Microhylinae & AB634626; AB634684 & Glyphoglossus yunnanensis \\
Microhylinae & KP682314 & Kaloula rugifera \\
Microhylinae & AB634634; AB634692 & Metaphrynella pollicaris \\
Microhylinae & AB634600; AB634658 & Microhyla annectens \\
Microhylinae & DQ512876 & Microhyla fissipes \\
Microhylinae & NC006406 & Microhyla heymonsi \\
Microhylinae & AB303950 & Microhyla okinavensis \\
Microhylinae & AB634616; AB634674 & Microhyla petrigena \\
Microhylinae & NC024547 & Microhyla pulchra \\
$\begin{array}{l}\text { Microhylinae } \\
\text { Microhylinae }\end{array}$ & AB598317; AB598341 & Micryletta inornata \\
Microhylinae & AB634638; AB634696 & Micryletta steinegeri \\
Microhylinae & AB634636; AB634694 & Phrynella pulchra \\
$\begin{array}{l}\text { Phrynomerinae } \\
\text { Scaphiophryninae }\end{array}$ & AB634633; AB634691 & Uperodon taprobanicus \\
Rhacophoridae & AB202078 634652 AB634710 & Phrynomantis bifasciatus \\
\hline
\end{tabular}

KUHE $33224 \quad$ Matsui et al., 2011

MZBAmp $15295 \quad$ Matsui et al., 2011

KUHE $53145 \quad$ Matsui et al., 2011

IND-18 Peloso et al., 2015

KUHE $35182 \quad$ Matsui et al., 2011

KUHE $44148 \quad$ Matsui et al., 2011

- Deng et al., 2015

KUZ-21655 Matsui et al., 2011

- $\quad$ Matsui et al., 2011

- $\quad$ unpublished

- $\quad$ Zhang et al., 2005

- $\quad$ Igawa et al., 2008

- $\quad$ Matsui et al., 2011

- Wu et al., 2014

KUHE $20497 \quad$ Matsui et al., 2011

KUHE 35937 Matsui et al., 2011

UKMHC $820 \quad$ Matsui et al., 2011

KUHE $37252 \quad$ Matsui et al., 2011

KUHE 33277 Matsui et al., 2011

KUHE $34977 \quad$ Matsui et al., 2011

Sano et al., 2005 


\section{Table 3 (on next page)}

Genetic divergence of Siamophryne troglodytes Gen. et sp. nov.

Uncorrected p-distances (percentage) between 12S rRNA - 16S rRNA sequences of

Siamophryne troglodytes Gen. et sp. nov. and other Microhylidae genera included in phylogenetic analyses (below the diagonal line), and standard error estimates (above the diagonal line). The mean uncorrected $p$-distances within those genera for which more than one specimen was examined are shown in the diagonal and shaded with grey. 


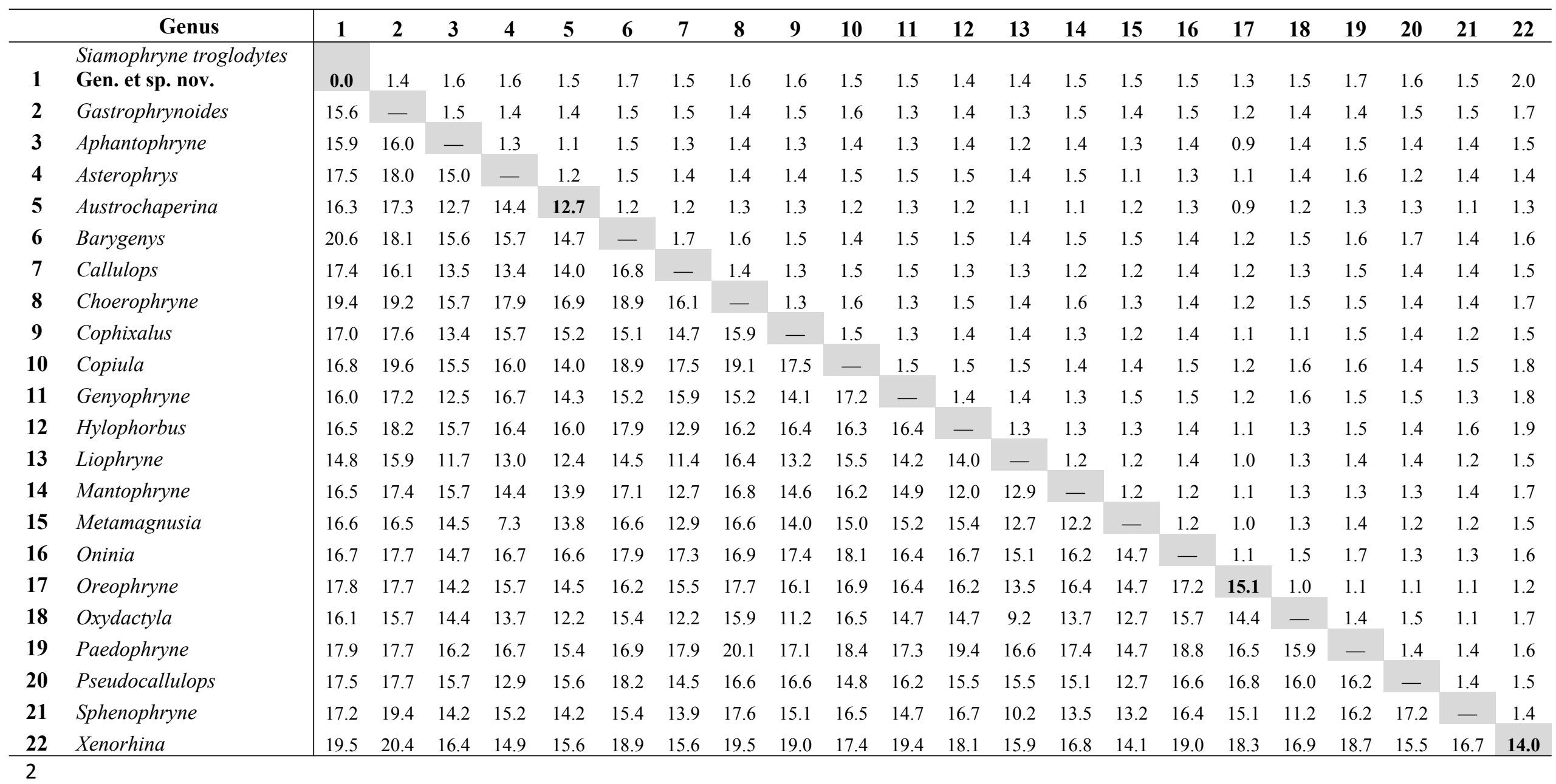




\section{Table 4(on next page)}

Measurement data for Siamophryne troglodytes Gen. et sp. nov. type series.

Abbreviations: $\mathrm{m}=$ male, $\mathrm{f}=$ female, $\mathrm{SD}=$ standard deviation, $\mathrm{n}=$ number of measured specimens. For other abbreviations see Materials and methods. All measurements are in mm. 


\begin{tabular}{|c|c|c|c|c|c|c|c|c|c|c|c|c|c|c|c|}
\hline \multirow{3}{*}{$\begin{array}{l}\text { Characters } \\
\text { Museum ID } \\
\text { Sex } \\
\end{array}$} & \multirow{3}{*}{ 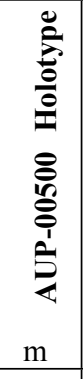 } & \multirow{3}{*}{ 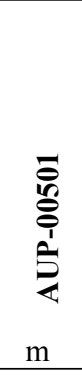 } & \multicolumn{4}{|c|}{ Paratype males } & \multirow[b]{3}{*}{$\operatorname{Mean} \pm$ SD } & \multirow[b]{3}{*}{ Min-Max } & \multirow{3}{*}{ 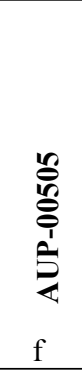 } & \multicolumn{3}{|c|}{ Paratype females } & \multirow{3}{*}{ 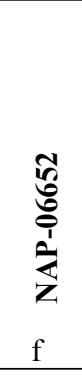 } & \multirow[b]{3}{*}{ Mean \pm SD } & \multirow[b]{3}{*}{ Min-Max } \\
\hline & & & 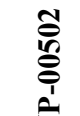 & 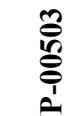 & 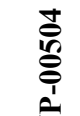 & $\begin{array}{l}\overline{0} \\
0 \\
0 \\
1 \\
1\end{array}$ & & & & $\begin{array}{l}\text { ஜ̊ } \\
\stackrel{8}{0} \\
\stackrel{1}{1}\end{array}$ & 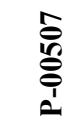 & $\begin{array}{l}\infty \\
\stackrel{0}{0} \\
0 \\
0 \\
1\end{array}$ & & & \\
\hline & & & $\mathrm{m}$ & $\mathrm{m}$ & $\mathrm{m}$ & $\mathrm{m}$ & & & & $\mathrm{f}$ & $\mathrm{f}$ & $\mathrm{f}$ & & & \\
\hline (1) SVL & 22.1 & 24.9 & 19.8 & 24.6 & 24.1 & 19.1 & $22.4 \pm 2.1$ & (19.1-24.9) & 26.6 & 25.9 & 25.0 & 27.8 & 26.1 & $26.3 \pm 0.7$ & $(25.0-27.8)$ \\
\hline (2) HL & 6.7 & 7.7 & 6.3 & 7.4 & 7.4 & 6.3 & $7.0 \pm 0.5$ & $(6.3-7.7)$ & 8.1 & 7.8 & 7.6 & 8.8 & 8.1 & $8.1 \pm 0.3$ & (7.6-8.8) \\
\hline (3) $\mathrm{SL}$ & 2.7 & 2.7 & 2.4 & 2.9 & 2.8 & 2.2 & $2.6 \pm 0.2$ & $(2.2-2.9)$ & 3.0 & 2.9 & 3.0 & 3.3 & 3.0 & $3.0 \pm 0.1$ & $(2.9-3.3)$ \\
\hline (4) EL & 3.0 & 3.2 & 2.5 & 3.0 & 2.8 & 2.4 & $2.8 \pm 0.2$ & $(2.4-3.2)$ & 3.3 & 3.6 & 3.2 & 3.4 & 3.0 & $3.3 \pm 0.2$ & $(3.0-3.6)$ \\
\hline (5) N-EL & 1.9 & 1.5 & 1.5 & 1.9 & 2.0 & 1.2 & $1.7 \pm 0.3$ & $(1.2-2.0)$ & 2.0 & 1.6 & 2.1 & 2.2 & 1.7 & $1.9 \pm 0.2$ & $(1.6-2.2)$ \\
\hline (6) HW & 7.1 & 7.6 & 6.6 & 8.6 & 7.5 & 6.6 & $7.3 \pm 0.6$ & (6.6-8.6) & 8.5 & 7.7 & 9.4 & 8.1 & 8.8 & $8.5 \pm 0.5$ & $(7.7-9.4)$ \\
\hline (7) IND & 2.3 & 2.3 & 1.9 & 2.4 & 2.4 & 1.7 & $2.2 \pm 0.2$ & $(1.7-2.4)$ & 2.6 & 2.7 & 2.5 & 2.8 & 2.7 & $2.6 \pm 0.1$ & $(2.5-2.8)$ \\
\hline (8) IOD & 2.2 & 2.4 & 1.4 & 2.4 & 2.5 & 2.0 & $2.1 \pm 0.3$ & (1.4-2.5) & 2.4 & 2.3 & 2.5 & 2.8 & 2.5 & $2.5 \pm 0.1$ & $(2.3-2.8)$ \\
\hline (9) UEW & 1.8 & 2.1 & 1.5 & 1.8 & 1.8 & 1.2 & $1.7 \pm 0.2$ & $(1.2-2.1)$ & 2.1 & 2.1 & 2.0 & 2.1 & 2.0 & $2.0 \pm 0.1$ & $(2.0-2.1)$ \\
\hline (10) FLL & 15.4 & 16.9 & 13.9 & 18.3 & 16.2 & 13.5 & $15.7 \pm 1.3$ & $(13.5-18.3)$ & 17.9 & 18.2 & 17.9 & 18.1 & 17.5 & $17.9 \pm 0.2$ & $(17.5-18.2)$ \\
\hline (11) LAL & 10.4 & 11.6 & 9.6 & 11.9 & 11.3 & 9.9 & $10.8 \pm 0.8$ & $(9.6-11.9)$ & 14.2 & 12.0 & 12.2 & 12.3 & 13.0 & $12.7 \pm 0.7$ & $(12.0-14.2)$ \\
\hline (12) HAL & 5.6 & 6.7 & 4.9 & 6.4 & 6.0 & 5.5 & $5.9 \pm 0.5$ & $(4.9-6.7)$ & 6.7 & 7.0 & 6.8 & 6.8 & 7.4 & $6.9 \pm 0.2$ & $(6.7-7.4)$ \\
\hline (13) IPTL & 1.0 & 1.1 & 0.9 & 1.0 & 1.0 & 0.5 & $0.9 \pm 0.1$ & $(0.5-1.1)$ & 1.0 & 0.8 & 1.0 & 1.0 & 1.0 & $1.0 \pm 0.1$ & $(0.8-1.0)$ \\
\hline (14) OPTL & 1.1 & 1.0 & 1.0 & 1.0 & 1.1 & 0.7 & $1.0 \pm 0.1$ & $(0.7-1.1)$ & 1.0 & 1.1 & 1.1 & 1.1 & 0.6 & $1.0 \pm 0.1$ & $(0.6-1.1)$ \\
\hline (15) HLL & 37.1 & 35.4 & 30.3 & 36.9 & 34.4 & 29.9 & $34.0 \pm 2.3$ & $(29.9-37.1)$ & 41.7 & 37.0 & 37.1 & 38.6 & 38.1 & $38.5 \pm 1.3$ & $(37.0-41.7)$ \\
\hline (16) TL & 10.8 & 10.1 & 10.0 & 12.4 & 11.5 & 9.7 & $10.7 \pm 0.8$ & $(9.7-12.4)$ & 13.3 & 10.2 & 12.8 & 13.2 & 12.3 & $12.4 \pm 0.9$ & $(10.2-13.3)$ \\
\hline (17) FL & 9.6 & 10.9 & 7.9 & 10.4 & 10.7 & 9.5 & $9.8 \pm 0.8$ & $(7.9-10.9)$ & 11.9 & 11.8 & 12.5 & 11.7 & 13.2 & $12.2 \pm 0.5$ & (11.7-13.2) \\
\hline (18) IMTL & 0.9 & 0.9 & 0.8 & 1.0 & 1.0 & 0.4 & $0.8 \pm 0.1$ & $(0.4-1.0)$ & 1.5 & 1.5 & 1.5 & 1.5 & 1.0 & $1.4 \pm 0.2$ & $(1.0-1.5)$ \\
\hline (19) 1TOEL & 2.0 & 2.1 & 2.9 & 3.2 & 2.4 & 1.3 & $2.3 \pm 0.5$ & $(1.3-3.2)$ & 2.9 & 2.2 & 2.5 & 2.7 & 1.8 & $2.4 \pm 0.3$ & $(1.8-2.9)$ \\
\hline (20) 2TOEL & 4.7 & 4.6 & 4.7 & 5.7 & 4.9 & 2.4 & $4.5 \pm 0.7$ & $(2.4-5.7)$ & 5.8 & 4.6 & 4.5 & 4.5 & 4.0 & $4.7 \pm 0.4$ & $(4.0-5.8)$ \\
\hline (21) 3TOEL & 7.4 & 7.5 & 7.1 & 8.1 & 8.2 & 3.9 & $7.0 \pm 1.0$ & (3.9-8.2) & 9.3 & 8.6 & 8.2 & 7.6 & 5.6 & $7.8 \pm 1.0$ & $(5.6-9.3)$ \\
\hline (22) 4TOEL & 9.6 & 10.9 & 7.9 & 10.4 & 10.7 & 8.7 & $9.7 \pm 1.0$ & $(7.9-10.9)$ & 11.9 & 11.8 & 12.5 & 11.7 & 12.5 & $12.1 \pm 0.3$ & $(11.7-12.5)$ \\
\hline (23) 5TOEL & 7.3 & 6.6 & 6.3 & 7.6 & 7.8 & 2.8 & $6.4 \pm 1.2$ & $(2.8-7.8)$ & 8.7 & 7.6 & 7.7 & 7.1 & 8.8 & $8.0 \pm 0.6$ & (7.1-8.8) \\
\hline (24) $1 \mathrm{FW}$ & 1.0 & 1.0 & 0.7 & 1.0 & 0.9 & 0.5 & $0.8 \pm 0.2$ & $(0.5-1.0)$ & 0.8 & 1.0 & 1.1 & 1.1 & 0.6 & $0.9 \pm 0.2$ & $(0.6-1.1)$ \\
\hline (25) $2 \mathrm{FDW}$ & 1.2 & 1.3 & 1.0 & 1.3 & 1.0 & 0.7 & $1.1 \pm 0.1$ & $(0.7-1.3)$ & 1.6 & 1.6 & 1.3 & 1.4 & 1.2 & $1.4 \pm 0.1$ & $(1.2-1.6)$ \\
\hline (26) 3FDW & 1.3 & 1.3 & 1.2 & 1.2 & 1.1 & 1.0 & $1.2 \pm 0.1$ & $(1.0-1.3)$ & 1.5 & 1.5 & 1.4 & 1.6 & 1.3 & $1.4 \pm 0.1$ & $(1.3-1.6)$ \\
\hline (27) 4FDW & 1.3 & 1.4 & 1.2 & 1.3 & 1.2 & 0.8 & $1.2 \pm 0.1$ & $(0.8-1.4)$ & 1.3 & 1.6 & 1.4 & 1.5 & 1.1 & $1.4 \pm 0.1$ & $(1.1-1.6)$ \\
\hline (28) $1 \mathrm{TDW}$ & 0.2 & 0.2 & 0.2 & 0.2 & 0.2 & 0.3 & $0.2 \pm 0.0$ & $(0.2-0.3)$ & 0.2 & 0.2 & 0.2 & 0.2 & 0.5 & $0.3 \pm 0.1$ & $(0.2-0.5)$ \\
\hline (29) $2 \mathrm{TDW}$ & 0.2 & 0.2 & 0.2 & 0.2 & 0.2 & 0.8 & $0.3 \pm 0.1$ & $(0.2-0.8)$ & 0.2 & 0.2 & 0.2 & 0.2 & 0.8 & $0.3 \pm 0.1$ & $(0.2-0.8)$ \\
\hline (30) 3TDW & 0.3 & 0.3 & 0.3 & 0.2 & 0.2 & 0.7 & $0.3 \pm 0.1$ & $(0.2-0.7)$ & 0.2 & 0.2 & 0.3 & 0.2 & 1.0 & $0.4 \pm 0.1$ & $(0.2-1.0)$ \\
\hline (31) 4TDW & 0.5 & 0.6 & 0.5 & 0.6 & 0.6 & 0.6 & $0.6 \pm 0.0$ & $(0.5-0.6)$ & 0.6 & 0.6 & 0.6 & 0.7 & 1.1 & $0.7 \pm 0.2$ & $(0.6-1.1)$ \\
\hline (32) $5 \mathrm{TDW}$ & 0.3 & 0.3 & 0.3 & 0.3 & 0.3 & 0.5 & $0.3 \pm 0.1$ & $(0.3-0.5)$ & 0.3 & 0.3 & 0.3 & 0.4 & 0.6 & $0.4 \pm 0.1$ & $(0.3-0.6)$ \\
\hline (33) $1 \mathrm{FLO}$ & 1.9 & 2.2 & 2.1 & 3.3 & 3.2 & 1.3 & $2.3 \pm 0.5$ & $(1.3-3.3)$ & 2.9 & 2.8 & 1.9 & 2.8 & 1.9 & $2.4 \pm 0.4$ & (1.9-2.9) \\
\hline (34) $2 \mathrm{FLO}$ & 3.7 & 4.8 & 3.5 & 5.7 & 5.2 & 2.4 & $4.2 \pm 0.9$ & $(2.4-5.7)$ & 4.7 & 4.7 & 3.8 & 4.0 & 3.8 & $4.2 \pm 0.4$ & $(3.8-4.7)$ \\
\hline
\end{tabular}




\begin{tabular}{|c|c|c|c|c|c|c|c|c|c|c|c|c|c|c|c|}
\hline (35) $3 \mathrm{FLO}$ & 5.6 & 6.4 & 5.0 & 6.9 & 6.7 & 3.2 & $5.6 \pm 1.0$ & $(3.2-6.9)$ & 6.6 & 6.7 & 5.2 & 6.2 & 4.3 & $5.8 \pm 0.8$ & $(4.3-6.7)$ \\
\hline (36) 4FLI & 4.5 & 4.9 & 3.9 & 6.0 & 6.2 & 2.6 & $4.7 \pm 1.0$ & $(2.6-6.2)$ & 5.5 & 4.8 & 3.2 & 5.4 & 3.1 & $4.4 \pm 1.0$ & $(3.1-5.5)$ \\
\hline (37) TMP & 1.2 & 1.5 & 1.1 & 1.4 & 1.3 & 1.1 & $1.3 \pm 0.1$ & (1.1-1.5) & 1.4 & 1.5 & 1.6 & 1.1 & 1.6 & $1.4 \pm 0.2$ & (1.1-1.6) \\
\hline (38) TEY & 0.8 & 0.7 & 0.6 & 0.6 & 0.7 & 0.6 & $0.7 \pm 0.1$ & $(0.6-0.8)$ & 0.6 & 0.7 & 1.0 & 0.6 & 0.6 & $0.7 \pm 0.1$ & $(0.6-1.0)$ \\
\hline
\end{tabular}
1 